
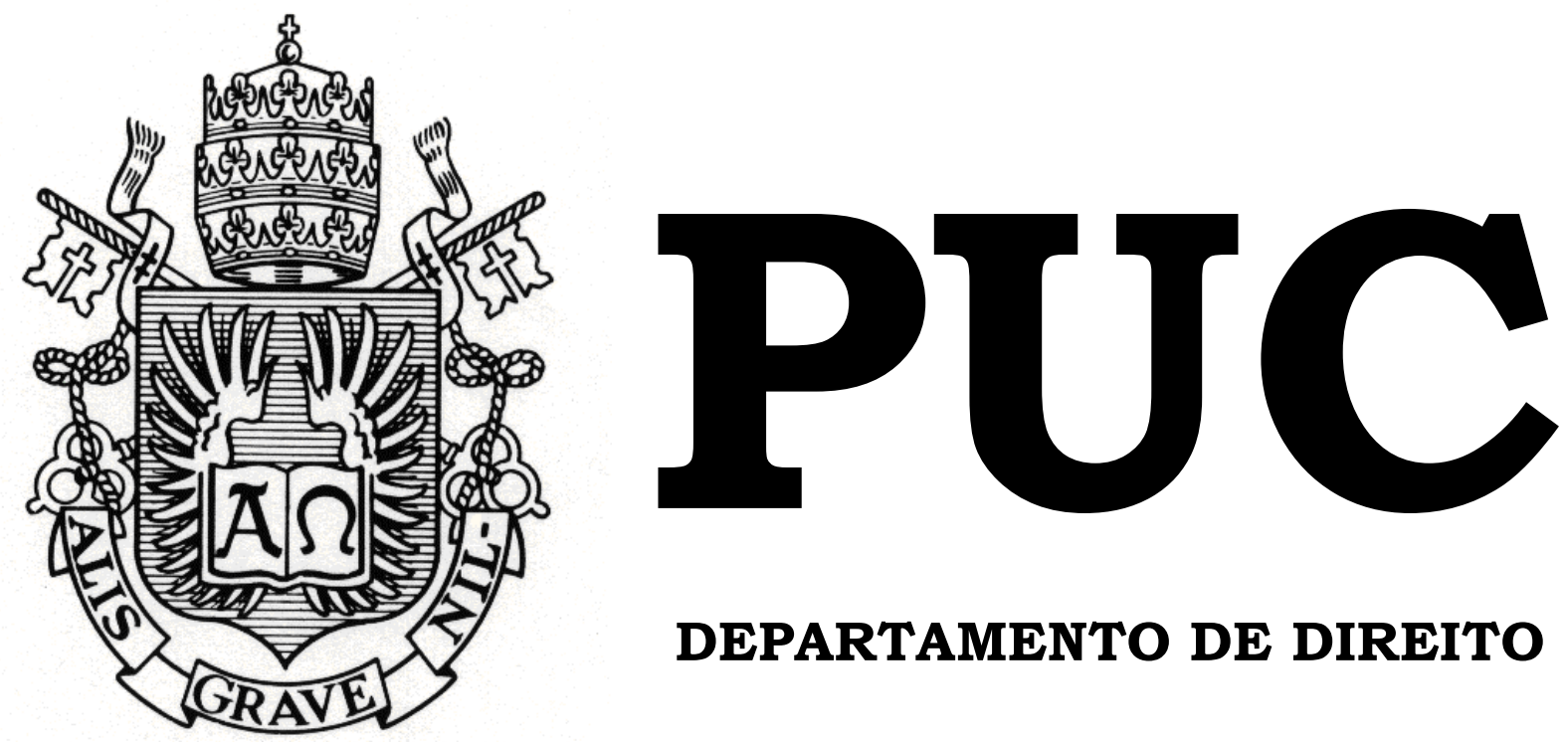

DEPARTAMENTO DE DIREITO

Manipulação de Mercado:

Análise da Manipulação de Informações

Sob a Luz das Novas Tecnologias no Âmbito do Direito Brasileiro e Norte Americano

por

Leandro Bittencourt da Rocha Silva Ramos

ORIENTADORA: Norma Jonssen Parente

2016.2

PONTIFÍCIA UNIVERSIDADE CATÓLICA DO RIO DE JANEIRO

RUA MARQUÊS DE SÃO VICENTE, 225 - CEP 22453-900

RIO DE JANEIRO - BRASIL 


\section{Manipulação de Mercado: \\ Análise da Manipulação de Informações Sob a Luz das Novas Tecnologias no Âmbito do Direito Brasileiro e Norte Americano}

por

Leandro Bittencourt da Rocha Silva Ramos

Monografia apresentada ao Departamento de Direito da Pontificia Universidade Católica do Rio de Janeiro (PUCRio) para a obtenção do Título de Bacharel em Direito.

Orientadora: Norma Jonssen Parente 


\section{Agradecimentos}

Meu primeiro agradecimento fica para meu grande amigo Arthur Ramos. A inspiração para o tema deste trabalho começou com seu despretensioso presente de aniversário, um livro chamado "Acredite, Estou Mentindo", do Ryan Holiday. Um simples presente de aniversário me fez ficar apaixonado pelo tema, ao ponto de mudar o tema da minha monografia que já havia decidido desde o segundo período de faculdade.

Também é necessário dar o devido mérito à Isabela Klein, minha revisora, consultora e maior apoiadora. Exemplo de pessoa que te faz caminhar sempre para frente, ela faz muito com pouco e lida com grandes problemas como se nada fossem.

Fica aqui, também, meu agradecimento à Nicholas Sousa, uma das pessoas mais competentes, atenciosas e concentradas que conheço. Sua dedicação em sempre tentar tirar o melhor de mim e puxar minhas orelhas quando necessário (e ainda assim não desistir de mim) só aumenta ainda mais minha admiração.

À professora Norma que, com sua excelente aula, me fazia ir para PUC com prazer e me incentivou a escrever sobre este tema.

Por fim, fica também um agradecimento à Luciano Leite, Lygia Marina e Rodolfo Costa, que ficaram madrugadas me ouvindo, com toda a paciência do mundo, divagar sobre este tema. 


\section{Resumos e Palavras-Chave}

RAMOS, Leandro Bittencourt da Rocha Silva. Manipulação de Mercado: Análise da Manipulação de Informações Sob a Luz das Novas Tecnologias no Âmbito do Direito Brasileiro e Norte Americano. 61p., 2016. Monografia (Graduação em Direito) - Pontifícia Universidade Católica do Rio de Janeiro - PUC-RJ: Rio de Janeiro, 2016.

O presente trabalho tem como primeiro objetivo promover uma análise e explicação de como funciona o sistema de transmissão de informações na era da internet. Além disso, esta monografia fará uma breve análise da legislação em vigor sobre a manipulação de mercado no Brasil e nos EUA. Também será analisado alguns tipos específicos de manipulação, comumente utilizados na manipulação de mercado pela internet ou pelas mídias de comunicação. Por fim, será feita uma análise de diferentes casos no Brasil e nos EUA envolvendo manipulação de mercado pela internet e mídias de comunicação.

Palavras Chave: Direito Societário - Mercado de Capitais - Mercado de Valores Mobiliários - Manipulação de Mercado - Internet - SEC - CVM Condições Artificiais de Demanda - Operações Fraudulentas Manipulação de Preços. 


\section{Sumário}

Capítulo 1 - Introdução

1.1. Colocação da Questão 7

1.2. Delimitação do Tema 8

Capítulo 2 - Os Meios de Circulação de Informação 10

2.1. A Estrutura Financeira dos Sites 10

2.2. Como as informações se movimentam pelo Sistema. 14

2.3. Casos de manipulação da Mídia 17

2.3.1. A Vitória da Coréia do Norte na Copa do Mundo de $2014 \quad 17$

2.3.2. O caso de Tim Pawlenty 18

Capítulo 3 - Manipulação de Mercado 20

3.1. O Brasil e a CVM 20

3.2. Os EUA e a SEC 23

3.2.1. As Blue Sky Laws $\quad 23$

3.2.2. Securities Act de 1933

3.2.3. Securities Exchange Act de 1934 e a Rule 10b-5 25

3.2.4. Trust Indenture Act de 1939

3.2.5. Investment Company Act de $1940 \quad 27$

3.2.6. Investment Advisers Act de 1940

3.2.7. Sarbanes-Oxley Act de $2002 \quad 27$

3.2.8. Dodd-Frank Wall Street Reform and Consumer Protection Act de $2010 \quad 28$

3.2.9. Jumpstart Our Business Startups Act de 2012

3.3. Manipulação de mercado pela Internet. 28

Capítulo 4 - Manipulação de Mercado em Espécie 32

4.1. Pump and Dump 32

4.2. Marking the Open/Marking the Close (Marking) 34

Capítulo 5 - Análise de Casos nos EUA 36

5.1. SEC vs. Kenneth Terrel, Jason Wyckoff, Adam Altman e Joanne Colt 36

5.1.1. O Sistema de Manipulação 36

5.1.2. O Primeiro caso - Apache Medical Systems, Inc. 38

5.1.3. O Segundo Caso - Option Care 38

5.1.4. A Terceira Investida - American Education Corp. 39

5.1.5 A última investida - Artecon, Inc. 40

5.1.6. Consequências 41 
5.2. SEC vs Lambros Ballas 42

5.2.1. Discovery Laboratories, Inc. $\quad 43$

5.2.2. IMAX/Disney 44

5.2.3. Local.com 45

5.2.4. Resultado 46

Capítulo 6 - Análise de casos no Brasil 48

6.1. Inquérito Administrativo CVM n. TA-RJ2001/6226 - Ciro Orenstein Ribeiro Tourinho 48

6.2 Processo Administrativo Sancionador CVM n.ำ RJ2013/5194 Metynis (Marambaia)

6.2.1. Quem é quem 49

6.2.2. Marking the Open/Close 50

6.2.3. A atuação nos fóruns de internet. 51

6.2.4. Os Fatos (ir)Relevantes 53

6.2.5. O Resultado 54

Capítulo 7 - Conclusão 55

$\begin{array}{ll}\text { BIBLIOGRAFIA } & 57\end{array}$ 


\section{Lista de Abreviações}

BOVESPA

CEO

CVM

EUA

FDA

NASDAQ

SEC
BM\&FBOVESPA

Chief Executive Officer

Comissão de Valores Mobiliários

Estados Unidos da América

Food and Drug Administration

NASDAQ Stock Market

Securities Exchange Comission 


\section{Capítulo 1 - Introdução}

\subsection{Colocação da Questão}

Com a evolução das tecnologias de comunicação, toda a transmissão de informação vem se tornando cada vez mais fácil.

No mercado de capitais tivemos grandes avanços ao incorporar o telégrafo, stock ticker, ${ }^{1}$ rádio, telefone, televisão e internet. Cada novo meio adaptado e utilizado pelo mercado acelerava consideravelmente a transmissão de informações, bem como a divulgação das informações aos investidores.

No entanto, com a chegada da internet, houve uma mudança na sociedade em níveis que nunca tinham sido vistos antes. A rádio demorou 38 anos para conseguir alcançar 50 milhões de usuários, a televisão levou 13 anos, enquanto a internet demorou apenas 4 anos. O Google conseguiu esse número de usuários em apensa 88 dias. $^{2}$ Em primeiro de julho de 2016, o número estimado de usuários da internet era de 3.424.971.237. ${ }^{3}$

Com esse novo alcance e velocidade, uma das coisas que mais cresceu nesse meio foi o comércio online. Qualquer pessoa pode criar um website para promover, vender, anunciar ou disseminar informação.

Isso ajudou a evoluir o mercado de capitais. As informações financeiras não são mais um privilégio das bolsas de valores, agora são públicas para todos os investidores que quiserem acessá-las. Além disso, os fóruns de discussão na internet têm se tornado cada vez mais comuns e são muito utilizados pelos investidores para analisar as tendências das companhias.

\footnotetext{
${ }^{1}$ Uma máquina parecida com o telégrafo, que transmitia informações em alta velocidade e imprime o símbolo da ação, número de ações e a variação do valor da ação. Veja mais em First stock ticker debuts. $\langle$ http://www.history.com/this-day-in-history/first-stock-ticker-debuts $>$, Acesso em 23/11/2016.

${ }^{2}$ It took radio 38 years to reach 50 million people... <http://digitalstats.blogspot.com.br/2011/04/it-took-radio-38-years-to-reach-50.html $>$, Acesso em 23/11/2016

${ }^{3}$ Internet Users. $<\underline{\mathrm{http}}: / / \mathrm{www}$. internetlivestats.com/internet-users/\#trend $>$ Acesso em 23/11/2016.
} 
Mas nem tudo são flores. Com esses grandes benefícios, vêm também grandes oportunidades para manipular o preço das ações no mercado. Apenas um comentário em um fórum de discussão ou uma reportagem negativa já é o suficiente para fazer a ação subir ou descer em níveis expressivos.

Em função da imensa velocidade com que a internet evolui e nos influencia, muitos têm dificuldade de acompanhar o avanço tecnológico da internet. Essa máxima se aplica de maneira muito mais impactante à legislação sobre o assunto. Tendo em vista o processo lento de elaboração e aprovação de leis (comparado à velocidade que a informação viaja, não há sistema legislativo que seja rápido o suficiente), não há legislação que consiga acompanhar a internet.

Muito, então, fica na mão das agências reguladoras, que são obrigadas a se desdobrar, investigar, interpretar, adaptar, regular toda e qualquer outra atividade que se faça necessária para evoluir e adequar o mercado à realidade atual. Como destacado pela ex diretora da CVM, Norma Parente:

"[d]a mesma forma que a Internet, de um lado, representa um avanço considerável na divulgação instantânea das informações e ampliou os meios de comunicação entre as pessoas, de outro, exige que a mesma seja utilizada com responsabilidade, uma vez que as consequências e alcance são imprevisíveis. Daí a necessidade de se inibir toda e qualquer iniciativa de seu uso indevido, por mínimo, que seja, por parte dos órgãos governamentais como a CVM, responsável pelo mercado de capitais." ${ }^{4}$

\subsection{Delimitação do Tema}

A temática a ser aqui analisada é a manipulação de mercado por meio da utilização das novas tecnologias de transmissão de informação, especialmente a internet, no Brasil e nos Estados Unidos.

Este trabalho abordará apenas os tipos de manipulação de mercado

\footnotetext{
${ }^{4}$ Inquérito Administrativo CVM n. ${ }^{\circ}$ TA-RJ2001/6226, julgado em 15 de maio de 2003, Relatora: Norma Jonssen Parente. Disponível em <http://www.cvm.gov.br/export/sites/cvm/sancionadores/sancionador/anexos/2003/20030515 PA S RJ20016226.pdf >, Acesso em 23/11/2016.
} 
de extrema importância para a questão ou que se façam necessários para a compreensão dos casos que serão analisados. De maneira alguma pretendese esgotar o tema - missão que se mostraria hercúlea para qualquer pessoa.

O objetivo do presente trabalho é chamar a atenção e estimular a discussão sobre um assunto tão presente no mundo atual, seja no âmbito do mercado de capitais ou até mesmo no âmbito pessoal, mas que não é ainda muito abordado pela doutrina, imprensa ou o legislativo.

O segundo capítulo aborda o sistema de transmissão de informações nos dias atuais. Seu propósito é iniciar o leitor nas atuais dinâmicas de funcionamento da internet, de como o jornalismo se adaptou a nova realidade e de como as pessoas exploram esse sistema para conseguir manipular a informação.

O terceiro capítulo aborda a evolução legislativa da CVM e da SEC que regulam o mercado quanto a sua manipulação, com o intuito de prover o leitor, investidor, acadêmicos e interessados com um guia legislativo e prática de mercado sobre a matéria.

O quarto capítulo aborda alguns tipos de manipulação de mercado em espécie, essenciais para compreensão de como funciona a manipulação de mercado pela internet e/ou dos casos que analisados neste trabalho.

O quinto capítulo faz uma análise dos casos julgados pela CVM sobre o assunto, de maneira a demonstrar como a manipulação tem sido utilizada no Brasil e como a CVM tem reagido a esse tipo de ilícito.

O sexto capítulo faz uma análise dos casos analisados pela SEC sobre o assunto, de maneira a demonstrar como a manipulação tem sido utilizada nos EUA e como a SEC tem reagido a esse tipo de ilícito. 


\section{Capítulo 2 - Os Meios de Circulação de Informação}

Antes de adentrar no tema principal, primeiramente, é necessário entender como, atualmente, a informação circula nos meios de comunicação. Além disso, é essencial compreender como funciona a estrutura de todos os websites, blogs, plataformas pessoais, fóruns de internet, enfim, toda a estrutura englobada dentro da internet (muitas vezes chamada de blogosfera), para que possamos compreender como as informações podem ser distorcidas e alteradas.

A internet conta com um número imenso de websites que transmitem informações ao público, desde plataformas pessoais, como Twitter e Facebook, passando por podcasts, videocasts, canais do youtube, e indo até os websites de grandes jornais. Para facilitar a compreensão, sempre que a palavra "Site" for utilizada, ela irá se referir a qualquer tipo de plataformas disponíveis na internet, bem como as publicações feitas em tais plataformas.

\subsection{A Estrutura Financeira dos Sites}

Antes de explicar como as informações são transmitidas pelo sistema, é necessário entender a estrutura de funcionamento dos Sites.

A principal fonte de renda dos Sites é a venda de espaço para anúncios. Alguns tipos de Sites possuem algumas outras formas de rendas, como inscrições pagas, ${ }^{5}$ contratos com empresas ${ }^{6}$ ou programas de

\footnotetext{
${ }^{5}$ Sites como Exame, O Globo, Latin Lawyer, Huffington Post e muitos outros possuem áreas restritas para assinantes.

${ }^{6}$ Nesse caso é fácil lembrar o caso recente do perfil do Twitter e Facebook denominado "Dilma Bolada", que foi contratado pelo PT para fazer campanha pró Dilma. COUTINHO, Filipe. Agência contratada pelo PT paga $R \$ 20$ mil de salário a criador de Dilma Bolada. 〈http://epoca.globo.com/tempo/noticia/2015/08/agencia-contratada-pelo-pt-paga-r-20-mil-desalario-dilma-bolada.html $>$, Acesso em 23/11/2016.
} 
recomendação ${ }^{7}$, mas, em geral, a fonte vem principalmente de anúncios.

Um bom exemplo da imensa escala que os anúncios podem fazer na receita das empresas é o Google, que vive, basicamente, de anúncios. Nas próprias demonstrações financeiras do Google é anunciado que "We generate revenue primarily by delivering relevant, cost-effective online advertising". 8

Assim, para conseguir lucro, os Sites vendem espaços para anúncios que, em sua maioria, são pagos por visualização. Partindo dessa informação, Ryan Holiday simplificou o modo de calcular o lucro dos Sites por uma simples fórmula: Tamanho do Anúncio x Tráfego (visualizações) = Receita. ${ }^{9}$ Como o espaço para anúncio nos Sites é limitado, os donos destes procuram aumentar o outro lado da equação, as visualizações.

Isso nos leva para o ponto seguinte: qual a melhor maneira de se aumentar as visualizações de um Site? Uma das melhores soluções encontradas pelos redatores foi pela obtenção de furos jornalísticos, os quais conseguem atrair grandes quantidades de leitores em um curto espaço de tempo, ainda mais quando se trata de informação exclusiva.

O exemplo disso é o Site TMZ (que hoje também possui um programa de televisão), o qual se especializou em furos de celebridades. Somente com esse tipo de abordagem, o TMZ anunciou, em 2008, um lucro de US\$25 milhões ${ }^{10}$ e, em 2010, chegou a ser avaliado por Sites em mais de

\footnotetext{
${ }^{7}$ Indicações de determinados produtos em um website específico que paga uma comissão caso a compra seja realizada. Para mais informações veja <http://www.maisrendaagora.com/comoganhar-dinheiro-na-internet-programa-de-afiliados/>, Acesso em 23/11/2016.

8 À título informativo, vale a pena acessar a reportagem da Investopedia <http://www.investopedia.com/stock-analysis/2012/what-does-google-actually-make-money-

from-goog1121.aspx $>, \quad$ Acesso em 08/11/2016, e da BBC
〈http://www.bbc.co.uk/guides/z9x6bk7>, Acesso em 08/11/2016, para uma informação detalhada de como o Google gera suas receitas.

${ }^{9}$ HOLIDAY, Ryan. Acredite, Estou mentindo: confissões deum manipulador de mídia. $1^{\text {a }}$ ed. São Paulo. Companhia Editora Nacional, 2012, p. 38.

10 FLINT, Joe. Time Warner wants more revenue from TMZ. $<$ http://articles.latimes.com/2009/dec/09/business/la-fi-ct-tmz9-2009dec09>, Acesso em 12/11/2016.
} 
US\$100 milhões. ${ }^{11}$

O TMZ já publicou notórios furos, como o escândalo envolvendo a agressão do cantor Chris Brown em sua então namorada Rihanna ${ }^{12}$ e a morte de Michael Jackson. ${ }^{13}$ No entanto, também já publicou furos falsos como, por exemplo, a suposta foto (nada nítida) do ex presidente dos EUA, John Kennedy, em um iate com várias mulheres nuas sob o título "A foto que poderia ter mudado a história". ${ }^{14}$ No final, o elemento da foto não era o ex presidente, mas sim um modelo pago da Playboy e a foto era de uma publicação de 1967 da revista. ${ }^{15}$ Lamentavelmente, a mídia entende que o importante não é, necessariamente, a verdade, mas sim a quantidade de pessoas que a matéria traz.

Outra coisa que precisamos ter em mente é que os Sites são feitos para serem vendidos. Apesar de conseguirem um bom dinheiro com publicidade, a melhor opção é sempre entrar debaixo da asa de uma grande empresa. ${ }^{16}$ Assim, além dos Sites serem vendidos por um valor alto, muitas vezes seus idealizadores continuam escrevendo em seus Sites, só que agora como empregados da empresa que os comprou.

Essa necessidade por visualizações muda o paradigma da transmissão da informação. Enquanto antigamente as notícias eram pesquisadas e elaboradas em dias, atualmente, a preferência é pela velocidade e quantidade de notícias.

Corroborando essa teoria, Bem Parr, um editor (à época) do Mashable, destacou que "Nós precisamos de gente que possa soltar uma

11 MCINTYRE, Douglas A. TMZ.com Valuation Tops \$100 Million . $<$ http://www.marketwatch.com/story/tmzcom-valuation-tops-100-million-2010-01-03> Acesso em 12/11/2016.

${ }^{12}$ EQUIPE TMZ. Brutal Rihanna Photos Surface < http://www.tmz.com/2011/02/24/rihannaphotos-brutal-beating-chris-brown-attack-police-attack/>, Acesso em 12/11/2016.

${ }^{13}$ EQUIPE TMZ. Michael Jackson Dies <http://www.tmz.com/2009/06/25/michael-jackson-diesdeath-dead-cardiac-arrest/>, Acesso em 12/11/2016.

14 EQUIPE TMZ. The JFK Photo That Could Have Changed History. <http://www.tmz.com/2009/12/28/president-john-f-kennedy-photograph-jfk-photo-boat-yatchnude-naked-women-mediterranean-sea-jackie-kennedy-ted-kennedy-senator-george-smatherselection/>, Acesso em 12/11/2016.

${ }^{15}$ TMZ Falls For JFK Photo Hoax <http://www.thesmokinggun.com/documents/celebrity/tmzfalls-jfk-photo-hoax $>$, Acesso em 12/11/2016.

${ }^{16}$ HOLIDAY, Ryan. Ibidem. p.43. 
história em minutos e compor os textos maiores, opinativos, em um par de horas, não um par de dias.", além disso, ele afirmou que a experiência prévia com jornalismo seria apenas um extra. ${ }^{17}$

Antes dessa nova tendência, os Sites pagavam seus redatores por artigo publicado, em um valor de US\$4 a 5 por artigo (dependendo do tráfego que o redator atrai para o Site) por 125 artigos. ${ }^{18}$ Agora, o sistema enfatiza o tráfego que o indivíduo traz com cada artigo e o pagamento é baseado no número de visualizações que sua matéria conseguiu.

O Seeking Alpha, website financeiro valorizado por investidores do mercado de capitais, utiliza exatamente esse tipo de remuneração. Um redator precisa ter 100 mil visualizações para receber mil dólares; já a média de remuneração por artigo ficou em US\$58 nos primeiros seis meses do Site. ${ }^{19}$

Já o Site Business Insider utiliza uma conta bem simples para remunerar seus redatores: eles precisam trazer três vezes o número de visualizações que seriam necessárias para pagar o seu salário e seus benefícios. Um jornalista que recebe 6 mil dólares no mês precisaria, para se pagar, conseguir 600 mil visualizações mensais em seus artigos - um número bem alto para notícias comuns. Fazendo um cálculo aritmético, percebemos que esse jornalista recebe US\$60 mil ao ano e precisa movimentar um tráfego de 1,8 milhão de visualizações mensais para conseguir receber seu salário e não ser demitido. ${ }^{20}$

Quando analisamos a situação do Twitter, as coisas ficam mais descaradas. É possível pagar para celebridades postarem o que você quiser.

\footnotetext{
${ }^{17}$ What do the big tech blogs such as TechCrunch or Mashable look for when they hire writers? $<$ https://www.quora.com/What-do-the-big-tech-blogs-such-as-TechCrunch-or-Mashable-look-forwhen-they-hire-writers $>$, Acesso em 12/11/2016.

18 ROWSE, Darren. Weblogs Inc Pays $\$ 4$ per Post to Bloggers. $<$ http://www.problogger.net/weblogs-inc-pays-4-per-post-to-bloggers/>, Acesso em 12/11/2016.

${ }^{19}$ KAPLAN, David. Updated: Seeking Alpha On Track To Pay Its Bloggers \$1.2 Million This Year. <https://gigaom.com/2011/07/05/419-seeking-alpha-on-track-to-pay-its-bloggers-1-2million-this-year/>, Acesso em 12/11/2016

${ }^{20}$ BLODGET, Henry. More Than You Ever Wanted To Know About The Economics Of The Online News Business -- A TWEETIFESTO. <http://www.businessinsider.com/henry-blodget-more-thanyou-ever-wanted-to-know-about-the-economics-of-the-online-news-business-a-tweetifesto-20103?op=1/\#>, Acesso em 12/11/2016.
} 
Por exemplo, o site sponsoredtweets.com permite que as pessoas paguem para celebridades (dentre elas Kim e Khloe Kardashian ${ }^{21}$, Chris Brown, Avril Lavigne e muitos outros) para que elas escrevam o que o anunciante quiser. ${ }^{22}$ Para evitar que as pessoas sejam manipuladas por esses tweets, tanto o Brasil quanto os EUA, ${ }^{23}$ já regularam os anúncios feitos pelo Twitter: nos EUA é necessário usar utilizar a hashtag "\#ad" na sua publicação, já no Brasil é necessário usar a hashtag "\#publipost". ${ }^{24}$

Todas essas informações nos levam à mesma conclusão lógica: seja para pagar suas contas ou para ficarem ricos, os redatores do site farão de tudo para conseguir, dinheiro, visualizações e "furos" jornalísticos.

\subsection{Como as informações se movimentam pelo Sistema.}

Essa necessidade de escrever sobre assuntos novos, em pouco tempo e com grande frequência, é o principal motivo que faz o nosso sistema ficar tão suscetível à manipulação.

Para acompanhar a rapidez necessária na internet, os redatores dos Sites procuram por histórias em todos os lugares disponíveis na internet: fóruns de discussão, Facebook, Twitter, outros websites, comunicados a imprensa e qualquer outro lugar que esteja ao alcance. Os Sites maiores são um pouco mais criteriosos e estruturados e, na maior parte das vezes, utilizam como fonte os Sites menores, que, por sua vez, tiram suas fontes de

\footnotetext{
${ }^{21}$ Por curiosidade, um tweet da Kim Kardashian vale nada menos que US\$10 mil.

${ }^{22}$ THIER, Dave. Tucker Max's Rejected Twitter Campaign and Stab at Celebrity Endorsement. $<$ http://www.forbes.com/sites/davidthier/2012/02/07/tucker-maxs-rejected-twitter-campaign-andstab-at-celebrity-endorsement/\#75d2b8af6c72>, Acesso em 12/11/2016.

${ }^{23}$ VARNEY, Chelsea. Celebrity Twitter Ads: Regulations, Allegations and Selling Out. $<$ https://www.brandwatch.com/blog/celebrity-twitter-endorsements-regulations-allegations-andselling-out/>, Acesso em 12/11/2016.

${ }^{24}$ Aqui no Brasil, a blogueira Gabriela Pugliesi, detentora de Site sobre moda e vida saudável, já foi acusada de fazer publicidade disfarçada em 2014 e, em 2016, foi oficialmente advertida pelo Conselho Nacional de Autorregulamentação Publicitária (junto com a Ambev) por não ter indicado que seu post com uma garrafa da cerveja Skol era um anúncio publicitário. VEJA SÂO PAULO. Conar Adverte Gabriela Pugliesi por publicidade ilegal. <http://vejasp.abril.com.br/materia/conar-adverte-gabriela-pugliesi-por-publicidade-ilegal >, Acesso em 12/11/2016.
} 
lugares muitas vezes duvidosos.

Esse tipo de atitude é comum, aceita e ensinada no meio. A repórter Lindsay Robertson, que já trabalhou em diversas grandes empresas como Gawker, The Awl, The New York Post, The Huffington Post e Yahoo!, publicou em seu Tumblr pessoal que o redator deveria se concentrar em "uma faixa de blogs com tráfego menor, entendendo (corretamente) que atualmente o conteúdo é filtrado para cima tanto quanto para baixo, e com frequência os sites menores, com sua capacidade de vasculhar a internet mais agilmente e a fundo, funcionam como viveiro para os maiores" 2526 . Para comprovar que ela tinha $100 \%$ de razão, no mesmo dia, o Tumblr oficial da Newsweek reproduziu os ensinamentos de Lindsay. ${ }^{27}$

Corroborando ainda mais essa tese, em pesquisa feita pela universidade de George Washington e o Site Cision, 89\% dos redatores disseram que utilizam outros Sites para pesquisa de histórias, 65\% disse utilizar a mídia social (como Facebook e Linkedin) para conseguir histórias e 52\% utilizam serviços como o Twitter para suas histórias. Além disso, $61 \%$ deles admitiram usar a Wikipédia para suas pesquisas. ${ }^{28}$

Ademais, os próprios redatores consideraram que as informações provindas dessas fontes são menos confiáveis que informações obtidas pela mídia tradicional, pois as informações de mídias sociais não possuem checagem de fatos, verificações ou padrão de publicação. ${ }^{29}$

O assessor de imprensa do deputado norte americano Darrell Issa, Kurt Bardella, exemplifica bem a falta de checagem dos fatos que são

\footnotetext{
25 "[...]a lower traffic tier with the (correct) understanding that these days, content filters up as much as it filters down, and often the smaller sites, with their ability to dig deeper into the internet and be more nimble, act as farm teams for the larger ones."

${ }^{26}$ ROBERTSON, Lindsay. The Dos and Don'ts of Online Publicity, For Some Reason. $<$ http://lindsayrobertson-blog.tumblr.com/post/330892541/the-dos-and-donts-of-online-publicityfor-some>, Acesso em 12/11/2016.

27 NEWSWEEK. The Dos and Don'ts of Online Publicity, For Some Reason. <http://newsweek.tumblr.com/post/330924245/the-dos-and-donts-of-online-publicity-for-some>, Acesso em 12/11/2016.

${ }^{28}$ National Survey Finds Majority of Journalists Now Depend on Social Media for Story Research. $<$ http://www.cision.com/us/about/news/2010-press-releases/national-survey-finds-majority-ofjournalists-now-depend-on-social-media-for-story-research/>, Acesso em 12/11/2016.

${ }^{29}$ National Survey Finds Majority of Journalists Now Depend on Social Media for Story Research. Ibid.
} 
publicados:

"Algumas pessoas da imprensa, me parece, são simplesmente preguiçosas. Às vezes eu solto um comunicado que é reproduzido palavra por palavra. Isso é constrangedor. Eles estão se adaptando a uma época que exige menos qualidade e mais quantidade. E isso funciona a meu favor na maioria do tempo, porque acho que a maioria dos repórteres gosta que eu lhes entregue tudo pronto. A maioria das pessoas sempre opta pelo que é mais fácil, para que possa ir para a próxima tarefa. Repórteres são avaliados pela frequência com que seu material aparece no Drudge. É ruim que seja assim, mas é a realidade." ${ }^{30} 31$

Ryan Holiday ${ }^{32}$ esquematizou o sistema de transmissão de informação em 3 pontos principais: o primeiro nível é o ponto de entrada da informação, Sites pequenos, vorazes por visualizações, sempre à procura de uma grande história para atrair mais leitores. O segundo nível é de Sites mais influentes, os quais são mais seletivos com as informações que publicam, mas que estão sempre procurando em Sites menores, que consideram confiáveis, por novas histórias. Por último, temos o nível nacional. A grande notoriedade de alguma matéria nos outros níveis chama a atenção da mídia nacional, que se interessa especialmente em notícias que estão em alta no momento e ganhando força.

Scott Vener, conhecido por escolher músicas de programas renomados na $\mathrm{HBO}$, como, por exemplo, Entourage, é conhecido por ser um grande revelador de talentos. Seu modus operandi é exatamente o da mídia nacional: ele já admitiu que a maior parte da música descoberta por ele é o que está borbulhando na internet. ${ }^{33}$

Assim, essas vulnerabilidades óbvias se tornam prato cheio para pessoas que desejam manipular o sistema.

\footnotetext{
30 "Some people in the press, I think, are just lazy as hell. There are times when I pitch a story and they do it word for word. That's just embarrassing. They're adjusting to a time that demands less quality and more quantity. And it works to my advantage most of the time, because I think most reporters have liked me packaging things for them. Most people will opt for what's easier, so they can move on to the next thing. Reporters are measured by how often their stuff gets on Drudge. It's a bad way to be, but it's reality."

${ }^{31}$ LIZZA, Ryan. DON’T LOOK BACK. < http://www.newyorker.com/magazine/2011/01/24/dontlook-back-ryan-lizza>, Acesso em 12/11/2016.

${ }^{32}$ HOLIDAY, Ryan. Ibidem. p.27 e 28.

33 NPR STAFF. The Music Man Behind 'Entourage' Shares His Secret. 〈http://www.npr.org/2011/11/20/142558220/the-music-man-behind-entourage-shares-his-secret>, Acesso em 12/11/2016.
} 


\subsection{Casos de manipulação da Mídia}

\subsubsection{A Vitória da Coréia do Norte na Copa do Mundo de $2014^{34}$}

Um exemplo de sistema utilizado de forma inofensiva e engraçada foi quando o Site Não Salvo decidiu que tentaria completar o desafio de tornar a Coréia do Norte campeã da copa do mundo de 2014.

A brincadeira começou 3 meses antes da copa do mundo, quando o Não Salvo criou um canal no Youtube chamado "KOREA NEWS BACKUP", supostamente um canal de notícias da Coréia do Norte.

Durante 3 meses, colocaram vídeos falsos de reportagens passadas na Coréia do Norte. Por ser um país atualmente em ditadura, ninguém conseguia muitas notícias para confirmar as informações ali apresentadas.

Depois, após o início da copa do mundo, o Não Salvo colocou novos vídeos falsos em seu canal do Youtube, agora simulando diversas vitórias da Coréia do Norte na copa do mundo. Enquanto isso, colocavam outros vídeos (falsos) sobre assuntos aleatórios no canal, para manter a credibilidade do Site. Os vídeos das vitórias da Coréia do Norte rapidamente se tornaram virais e obtiveram 8 milhões de visualizações em 3 dias.

Com esse suposto furo jornalístico, conseguiram ingressar no primeiro nível do sistema: eles já tinham um Site (o canal do Youtube), o qual trazia informações supostamente confiáveis e agora tinha um furo jornalístico.

Rapidamente, o canal foi notado por um Site maior, o Twitter do jornalista Danilo Gentili. Com apenas um tweet dele sobre o assunto, o assunto começou rapidamente a ser viralizar no Brasil.

Para aumentar mais ainda a credibilidade, eles criaram um tópico no famoso fórum de discussões Reddit, para fornecer mais informações sobre o

\footnotetext{
34 Desafio Aceito 25 - Fazer a Coreia do Norte Campeã da Copa! $\langle$ http://www.naosalvo.com.br/desafio-aceito-25-fazer-da-coreia-do-norte-campea-da-copa/>, Acesso em 12/11/2016.
} 
assunto e, mais importante, internacionalizar o assunto.

Em pouco tempo, o jornal inglês Metro viu a discussão no Reddit e publicou em seu Site que a Coréia do Norte estaria dizendo aos seus fãs que o time estaria na final da copa do mundo. Com isso, diversos outros Sites (nacionais e internacionais) começaram a publicar a mesma notícia, dentre eles podemos listar: Independent UK, Mirror UK, ITV, O Canada, Business Insider, IB TIMES, Voice Of Russia, Futebol 365, Bleacher Report, The Wall Street Journal, Yahoo Sports, The Times of India, MensXP, Entertainment.ie, EuroSport UK, BuzzFeed, Sun News, CBC.ca, TorontoSun, Telegraph UK, The Epoch Times, UPI, Hello Kpop, IBN LIVE, Ghana Soccer Net, Total Pro Sports,FanSided, Tweaktown, Couriermail AU, JOE.ie, Tecmundo, Veja, O GLOBO, R7, Lance Net, Uol, Terra, Globo Esporte.

Eventualmente, usuários de fóruns de discussões da Coréia do Sul e do fórum 4Chan (outro fórum de discussão muito famoso) desconfiaram que os vídeos seriam falsos, mas por motivos completamente diversos da realidade. Aproveitando a deixa, o Não Salvo assumiu a autoria dos vídeos e explicou a brincadeira.

\subsubsection{O Caso de Tim Pawlenty}

Em época de eleições norte americanas, vale a pena relembrar um outro notório caso, o do governador do Minnesota, Tim Pawlenty.

Os Site políticos, diferentemente dos outros Sites, que podem escrever sobre diversos assuntos o ano inteiro, tem sua alta temporada em época de eleições. Então, para estenderem seu período lucrativo, os Sites políticos aumentam o período político.

Assim, começou a história de Pawlenty, governador de Minnesota e desconhecido no cenário político nacional. O Site Politico começou, desde 
$2010,{ }^{35}$ a acompanhar a trajetória (até então inexistente) da candidatura de Pawlenty à presidência.

Com isso, a campanha fictícia de Pawlenty foi ganhando força e passou a ser noticiada por vários outros Sites. ${ }^{36}$ Sua candidatura fictícia tornou-se, então, uma realidade.

Mais a frente, Pawlenty sofreu um revés na corrida presidencial e foi obrigado a retirar sua candidatura, mas o estrago já estava feito. Pawlenty passou de um governador desconhecido para uma figura importante.

Esse caso deu tamanha notoriedade à Pawlenty que até mesmo o candidato a presidência Mitt Romney (que concorria contra Barack Obama) foi pedir seu apoio publicamente. ${ }^{37}$

\footnotetext{
${ }^{35}$ Pawlenty budgets with an eye on 2012. < http://www.politico.com/story/2010/05/pawlentybudgets-with-an-eye-on-2012-037358>, Acesso em 12/11/2016.

36 PETERS, Jeremy W. Political Blogs Are Ready to Flood Campaign Trail <http://www.nytimes.com/2011/01/30/business/media/30blogs.html >, Acesso em 12/11/2016.

37 MUSKAL, Michael. Mitt Romney, Tim Pawlenty show support for Wisconsin governor

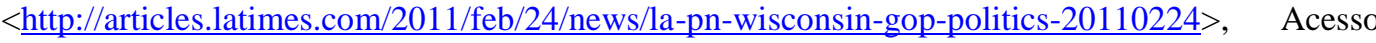
em 12/11/2016.
} 


\section{Capítulo 3 - Manipulação de Mercado}

\subsection{O Brasil e a CVM}

A primeira menção na nossa legislação à manipulação de mercado é encontrada no inciso VI do artigo $3^{\circ}$ da lei dos crimes contra a economia popular, n. ${ }^{\circ} 1.521$ de 26 de dezembro de 1951:

"Art. $3^{\circ}$. São também crimes desta natureza:

$[\ldots]$

VI - provocar a alta ou baixa de preços de mercadorias, títulos públicos, valores ou salários por meio de notícias falsas, operações fictícias ou qualquer outro artifício;"

Um dos notórios casos ligados a esse dispositivo é o do empresário Naji Nahas, responsável pela quebra da bolsa do Rio de Janeiro, o qual foi, inicialmente, condenado pela $25^{\mathrm{a}}$ Vara Federal do Rio de Janeiro e, posteriormente, inocentado pelo Tribunal Regional Federal e pelo STJ. ${ }^{38}$

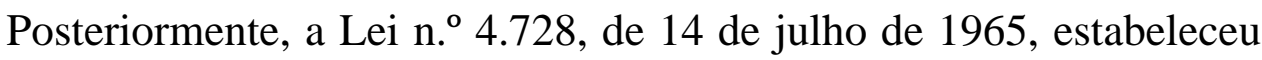
como um dos propósitos do Conselho Monetário Nacional e do Banco Central evitar a manipulação do mercado:

" Art. $2^{\circ} \mathrm{O}$ Conselho Monetário Nacional e o Banco Central exercerão as suas atribuições legais relativas aos mercados financeiro e de capitais com a finalidade de:

[...]

III - evitar modalidades de fraude e manipulação destinadas a criar condições artificiais da demanda, oferta ou preço de títulos ou valôres mobiliários distribuídos no mercado;

IV - assegurar a observância de práticas comerciais equitativas por todos aquêles que exerçam, profissionalmente, funções de intermediação na distribuição ou negociação de títulos ou valôres mobiliários;"

Ademais, a mesma lei estabeleceu que a competência para regular as normas do mercado seria do Conselho Monetário Nacional ("MN"), conforme o seu artigo 10, inciso VII.

"Art. 10. Compete ao Conselho Monetário Nacional fixar as normas gerais a serem observadas no exercício das atividades de subscrição para revenda,

38 SANDRINI, João. Decisão do STJ confirma absolvição do investidor Naji Nahas. < http://www1.folha.uol.com.br/folha/dinheiro/ult91u97763.shtml > Acesso em 23/11/2016. 
distribuição, ou intermediação na colocação, no mercado, de títulos ou valôres mobiliários, e relativos a:

$[\ldots]$

VII - normas destinadas a evitar manipulações de preço e operações fraudulentas;"

Em 7 de dezembro de 1976 foi instituída a Lei n. ${ }^{\circ}$ 6.385, a qual criou a CVM e é a atual lei que regula o mercado de valores mobiliários no Brasil. Nessa oportunidade, o artigo $4^{\circ}$ estabeleceu que é de competência do CMN e da CVM evitar a manipulação de mercado:

"Art . $4^{\circ} \mathrm{O}$ Conselho Monetário Nacional e a Comissão de Valores Mobiliários exercerão as atribuições previstas na lei para o fim de:

$[\ldots]$

V - evitar ou coibir modalidades de fraude ou manipulação destinadas a criar condições artificiais de demanda, oferta ou preço dos valores mobiliários negociados no mercado;

[...]

VII - assegurar a observância de práticas comerciais equitativas no mercado de valores mobiliários;"

Ademais, a mesma Lei n. ${ }^{\circ}$ 6.385/76 também estabeleceu como competência da CVM a regulação de normas de manipulação de mercado, conforme artigo 18, inciso II, b:

"Art. 18. Compete à Comissão de Valores Mobiliários:

$[\ldots]$

II - definir:

[...]

b) a configuração de condições artificiais de demanda, oferta ou preço de valores mobiliários, ou de manipulação de preço; operações fraudulentas e práticas não equitativas na distribuição ou intermediação de valores;"

Além disso, posteriormente, a mesma lei foi reformada, em 2001, para estabelecer a manipulação de mercado como um crime contra o mercado de capitais, nos termos do seu artigo 27-C:

"Art. 27-C. Realizar operações simuladas ou executar outras manobras fraudulentas, com a finalidade de alterar artificialmente o regular funcionamento dos mercados de valores mobiliários em bolsa de valores, de mercadorias e de futuros, no mercado de balcão ou no mercado de balcão organizado, com o fim de obter vantagem indevida ou lucro, para si ou para outrem, ou causar dano a terceiros"

Um emblemático caso envolvendo o supracitado artigo $27-\mathrm{C}$ foi o caso da Mundial, no qual, em suma, o Rafael Ferri (agente autônomo de investimento) recebeu informações privilegiadas de Michael Ceitlin (controlador e diretor presidente da Mundial S.A.) e por meio do esquema 
de pump and dump auferiram vantagens ilícitas. A grande notoriedade desse caso se dá devido ao fato que, pela primeira vez na história do Brasil, o Ministério Público Federal e a CVM (na condição de assistente de acusação) conseguiram a condenação penal pelo crime de manipulação de mercado. A sentença ${ }^{39}$ condenou Rafael Ferri e Michael Ceitlin pelos crimes de manipulação de mercado e uso de informação privilegiada, aplicando as seguintes penas:

"(i) CONDENAR o réu RAFAEL FERRI à pena privativa de liberdade estabelecida em 3 (três) anos e 9 (nove) meses de reclusão, a ser cumprida em regime inicial aberto, e ao pagamento de multas fixadas em $\mathrm{R} \$ 2.328 .382,00$ (dois milhões, trezentos e vinte e oito mil, trezentos e oitenta e dois reais), corrigidos monetariamente a partir de 26/07/2011, e em 31 (trinta e um) diasmulta, arbitrado o valor do diamulta em 15 (quinze) salários mínimos vigentes à época do fato (dezembro de 2010), atualizados até o efetivo pagamento, por incurso nas sanções dos arts. 27C e 27D, ambos da Lei n ${ }^{\circ}$ 6.385/76; e

(ii) CONDENAR o réu MICHAEL LENN CEITLIN à pena privativa de liberdade estabelecida em 3 (três) anos e 9 (nove) meses de reclusão, a ser cumprida em regime inicial aberto, e ao pagamento de multas fixadas em 85 (oitenta e cinco) diasmulta, arbitrado o valor do diamulta em 15 (quinze) salários mínimos vigentes à época do final dos fatos (julho de 2011), e em 31 (trinta e um) diasmulta, arbitrado o valor do diamulta em 15 (quinze) salários mínimos vigentes à época do fato (dezembro de 2010), atualizados até o efetivo pagamento, por incurso nas sanções dos arts. 27C e 27D, ambos da Lei $n^{\circ}$ 6.385/76."

Antes disso, a CVM já tinha aprofundado ainda mais o assunto ao editar sua própria legislação, por meio da Instrução CVM n. ${ }^{\circ} 8$, de 8 de outubro de 1979, a qual é, atualmente, a principal arma da CVM no combate à manipulação de mercado. Ela dispõe que:

"I - É vedada aos administradores e acionistas de companhias abertas, aos intermediários e aos demais participantes do mercado de valores mobiliários, a criação de condições artificiais de demanda, oferta ou preço de valores mobiliários, a manipulação de preço, a realização de operações fraudulentas e o uso de práticas não eqüitativas."

A própria Instrução n. ${ }^{\circ} 8$ da CVM, em seu segundo inciso, especifica os ilícitos citados em seu inciso I:

"II - Para os efeitos desta Instrução conceitua-se como:

a) condições artificiais de demanda, oferta ou preço de valores mobiliários

\footnotetext{
${ }^{39} 7^{\mathrm{a}}$ Vara da Justiça Federal de Porto Alegre. Ação Penal n. ${ }^{\circ}$ 506709618.2012.4.04.7100/RS, Juiz Federal Guilherme Beltrami, Porto Alegre, 7 de novembro de 2016. Disponível em 〈http://www.cvm.gov.br/export/sites/cvm/noticias/anexos/2016/20161111-sentenca-mundial.pdf>, Acesso em 23/11/2016.
} 
aquelas criadas em decorrência de negociações pelas quais seus participantes ou intermediários, por ação ou omissão dolosa provocarem, direta ou indiretamente, alterações no fluxo de ordens de compra ou venda de valores mobiliários;

b) manipulação de preços no mercado de valores mobiliários, a utilização de qualquer processo ou artifício destinado, direta ou indiretamente, a elevar, manter ou baixar a cotação de um valor mobiliário, induzindo, terceiros à sua compra e venda;

c) operação fraudulenta no mercado de valores mobiliários, aquela em que se utilize ardil ou artifício destinado a induzir ou manter terceiros em erro, com a finalidade de se obter vantagem ilícita de natureza patrimonial para as partes na operação, para o intermediário ou para terceiros;

d) prática não eqüitativa no mercado de valores mobiliários, aquela de que resulte, direta ou indiretamente, efetiva ou potencialmente, um tratamento para qualquer das partes, em negociações com valores mobiliários, que a coloque em uma indevida posição de desequilíbrio ou desigualdade em face dos demais participantes da operação."

\subsection{Os EUA e a SEC}

O mercado de capitais norte americano é atualmente regido por 8 leis federais, bem como por regulamentos internos editados pela SEC e as leis estaduais denominadas as Blue Sky Laws.

\subsubsection{As Blue Sky Laws}

De 1911 a 1933, as únicas leis que praticamente protegiam os investidores e os valores mobiliários no âmbito do mercado de capitais eram leis estaduais chamadas as "Blue Sky Laws" ${ }^{40}$. A origem do termo é polêmica: alguns alegam ${ }^{41}$ ser dos operadores de Kansas que seriam ousados ao ponto "vender o título absoluto de propriedade para construções de terrenos no céu azul" ${ }^{42}$ já outra corrente alega ${ }^{43}$ que o termo foi, primeiramente, usado por um juiz da Suprema Corte Norte Americana, no

\footnotetext{
40 MACEY, Jonathan; MILLER, Geoffrey. Origin of the Blue Sky Laws. $\langle$ http://digitalcommons.law.yale.edu/cgi/viewcontent.cgi?article=2679\&context=fss_papers $>$ p.348, Acesso em 08/11/2016.

41 MACEY, Jonathan; MILLER, Geoffrey. Origin of the Blue Sky Laws. $\langle$ http://digitalcommons.law.yale.edu/cgi/viewcontent.cgi?article=2679\&context=fss_papers $>\quad p$. 359, Acesso em 08/11/2016 e LOSS \& SELIGMAN, Fundamentals of securities regulation $-5^{\text {a }}$ Edição. Aspen Publishers, 2004, p. 10.

${ }^{42}$ Tradução livre da expressão "sell building lots in the blue sky in fee simple.".

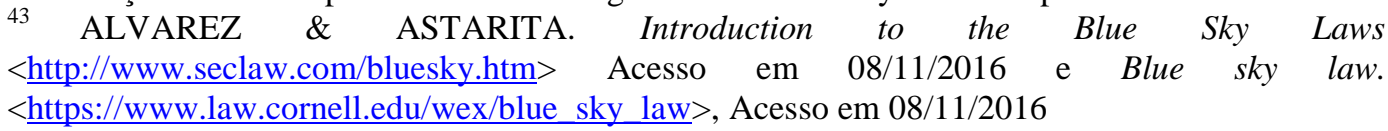


caso de Hall vs. Geiger-Jones Co. (1917), ao dizer que:

"The name that is given to the law indicates the evil at which it is aimed, that is, to use the language of a cited case, "speculative schemes which have no more basis than so many feet of 'blue sky"'; or, as stated by counsel in another case, "to stop the sale of stock in fly-by-night concerns, visionary oil wells, distant gold mines and other like fraudulent exploitations." Even if the descriptions be regarded as rhetorical, the existence of evil is indicated, and a belief of its detriment; and we shall not pause to do more than state that the prevention of deception is within the competency of government and that the appreciation of the consequences of it is not open for our review." ${ }^{44}$

O objetivo dessas leis era o mesmo em todos os Estados: regular o mercado e evitar fraudes. Seguindo o sistema jurídico norte americano, as leis variaram de Estado para Estado, mas, em geral, elas obrigavam o registro das ofertas de valores mobiliários e dos corretores ou firmas de corretagem. $^{45}$

Após a edição de diversas leis federais sobre o assunto, e, tendo em vista que muitas vezes as legislações federal e estadual se repetiam, boa parte das Blue Sky Laws foram revogadas por entrarem em conflito com leis federais. No entanto, as Blue Sky Laws não foram completamente abandonadas, e continuam agindo supletivamente às leis federais, ${ }^{46}$ como, por exemplo, no direito do Estado em realizar investigações e ajuizar ações contra esquemas de fraudes. ${ }^{47}$

\subsubsection{Securities Act de 1933}

Prosseguindo, a primeira grande legislação sobre o assunto foi o Securities Act de 1933 (também conhecida como Truth in Securities Act). ${ }^{48}$ A lei foi editada após a crise de 1929, causada exatamente pelo crash da bolsa de valores, também conhecida como "a Grande Depressão".

\footnotetext{
44 ALVAREZ \& ASTARITA. Introduction to the Blue Sky Laws <http://www.seclaw.com/bluesky.htm > Acesso em 08/11/2016

45 INVESTOPEDIA. Blue Sky Laws and the Securities Act of 1933. 〈http://www.investopedia.com/exam-guide/series-7/securities-markets/blue-sky-laws.asp $>$, Acesso em 08/11/2016 e ALVAREZ \& ASTARITA. Introduction to the Blue Sky Laws $<$ http://www.seclaw.com/bluesky.htm> Acesso em 08/11/2016.

${ }^{46}$ Disponível em: <https://www.sec.gov/answers/bluesky.htm>, Acesso em 08/11/2016.

47 ALVAREZ \& ASTARITA. Introduction to the Blue Sky Laws <http://www.seclaw.com/bluesky.htm > Acesso em 08/11/2016.

${ }^{48}$ Disponível em: < https://www.sec.gov/about/laws/sa33.pdf>, Acesso em 07/11/2016.
} 
Um dos principais pontos desta lei foi o disclosure de informações financeiras e outros tipos de informação aos investidores, bem como a proibição de falsidades e fraudes. Além disso, essa lei trouxe uma grande inovação: pela primeira vez, o entendimento sobre o mercado de capitais fora unificado sob uma só lei e no âmbito federal, bem como padronizou as leis paras os investidores, os quais, até então, estavam sujeitos às Blue Sky Laws de cada Estado.

\subsubsection{Securities Exchange Act de 1934 e a Rule 10b-5}

Em seguida, temos o Securities Echange Act de $1934,{ }^{49}$ o qual regula as transações de valores mobiliários no mercado secundário. Uma das principais inovações foi, em sua Section 4, a criação da SEC, entidade que até hoje regula e fiscaliza o mercado de capitais.

Com isso, passou à SEC a competência para fiscalizar vários membros do mercado. Assim, bolsas de valores (a NYSE e NASDAQ, por exemplo) passaram a ser obrigadas a manter registros com a SEC, nos termos da Section 5 e 6 :

"SEC. 5. It shall be unlawful for any broker, dealer, or exchange, directly or indirectly, to make use of the mails or any means or instrumentality of interstate commerce for the purpose of using any facility of an exchange within or subject to the jurisdiction of the United States to effect any transaction in a security, or to report any such transaction, unless such exchange (1) is registered as a national securities exchange under section 6 of this title, or (2) is exempted from such registration upon application by the exchange 67 SECURITIES EXCHANGE ACT OF 1934 Sec. 6 because, in the opinion of the Commission, by reason of the limited volume of transactions effected on such exchange, it is not practicable and not necessary or appropriate in the public interest or for the protection of investors to require such registration.

SEC. 6. (a) An exchange may be registered as a national securities exchange under the terms and conditions hereinafter provided in this section and in accordance with the provisions of section 19(a) of this title, by filing with the Commission an application for registration in such form as the Commission, by rule, may prescribe containing the rules of the exchange and such other information and documents as the Commission, by rule, may prescribe as necessary or appropriate in the public interest or for the protection of investors." (grifos nossos)

Quanto à questão da manipulação de mercado, a lei apresenta alguns

\footnotetext{
${ }^{49}$ Disponível em: < https://www.sec.gov/about/laws/sea34.pdf>, Acesso em 07/11/2016.
} 
artigos em específico para lidar com essas atitudes, como a cláusula 9 e a 10(b), 18 e 20. No entanto, muito se discute sobre o alcance de cada um desses dispositivos.

Por exemplo, a cláusula 9 se limitaria à manipulação de mercado feita apenas aos operadores (o que causou a quebra da bolsa de 1929), não se aplicando aos investidores. ${ }^{50}$ Já a cláusula 10 (b) é motivo de grande polêmica na Suprema Corte Americana. Há uma enorme discussão se esse dispositivo permitiria a SEC criar normas com um caráter mais amplo do que a própria cláusula estabelece. No entanto, nenhuma dessas discussões vem ao caso na presente análise.

Assim sendo, a SEC editou a Rule $10 \mathrm{~b}-5,{ }^{51}$ a sua principal arma contra os manipuladores de mercado, a qual complementou, ampliou e tornou mais precisa os dispositivos já existentes pelo Securities Exchange Act, nos seguintes termos.

"(a) General. The "manipulative and deceptive devices" prohibited by Section 10(b) of the Act (15 U.S.C. 78j) and \$240.10b-5 thereunder include, among other things, the purchase or sale of a security of any issuer, on the basis of material nonpublic information about that security or issuer, in breach of a duty of trust or confidence that is owed directly, indirectly, or derivatively, to the issuer of that security or the shareholders of that issuer, or to any other person who is the source of the material nonpublic information.

A Rule 10b-5 também é envolta em polêmica, sendo bastante discutida na doutrina e nas cortes norte americanas. No entanto, ela continua sendo a maior referência em casos de manipulação de mercado e é utilizada como o dispositivo aplicável pela SEC em suas acusações.

\subsubsection{Trust Indenture Act de $1939^{52}$}

Essa lei se refere especificamente aos valores mobiliários de dívida como debêntures, bonds e notes ofertadas ao público. Esses valores

\footnotetext{
${ }^{50}$ SARKAR, Deepa. Securities Exchange Act of 1934. https://www.law.cornell.edu/wex/securities_exchange_act of 1934, Acesso em 08/11/2016.

${ }^{51}$ Disponível em: <http://www.ecfr.gov/cgi-bin/text$\underline{\mathrm{idx}}$ ?node=17:4.0.1.1.1\&rgn=div5\#sg17.4.240.a.sg0 >, Acesso em 08/11/2016.

${ }^{52}$ Disponível em < https://www.sec.gov/about/laws/tia39.pdf $>$, Acesso em 08/11/2016.
} 
mobiliários devem ser registrados de acordo com o Securities Act (1933) mas somente podem ser ofertadas ao público caso um acordo formal seja celebrado entre o emissor dos bonds e os detentores dos bonds - chamado de trust indenture - esteja de acordo com o disposto nesta lei. ${ }^{53}$

\subsubsection{Investment Company Act de $1940^{54}$}

Diferentemente das anteriores, essa lei foca na organização das companhias que investem, reinvestem e negociam valores mobiliários e quem tem seus próprios valores mobiliários negociados. O objetivo dessa lei é diminuir os conflitos de interesses decorrentes das operações dessas companhias.

Para minimizar esses efeitos, elas são obrigadas a divulgar suas condições financeiras e suas políticas de investimento, para que os investidores tenham total conhecimento do modo de operação da companhia, sua estrutura e seus objetivos de investimento. ${ }^{55}$

\subsubsection{Investment Advisers Act de $1940^{56}$}

A quinta lei federal norte americana sobre o assunto regula os consultores de investimento. Exceto em hipóteses específicas, consultores que administrem ou deem consultoria em ativos com valor de pelo menos US\$100 milhões precisam se registrar perante a SEC e seguir determinadas regras por ela impostas. ${ }^{57}$

\subsubsection{Sarbanes-Oxley Act de $2002^{58}$}

A antepenúltima lei aqui examinada tem um foco mais empresarial. Ela modificou as questões de responsabilidade corporativa, divulgações de

\footnotetext{
${ }^{53}$ Disponível em <https://www.sec.gov/about/laws.shtml $>$, Acesso em 08/11/2016.

${ }^{54}$ Disponível em $\langle$ https://www.sec.gov/about/laws/ica40.pdf $>$, Acesso em 08/11/2016.

${ }^{55}$ Disponível em <https://www.sec.gov/about/laws.shtml $>$, Acesso em 08/11/2016.

${ }^{56}$ Disponível em $\langle$ https://www.sec.gov/about/laws/iaa40.pdf $>$, Acesso em 08/11/2016.

${ }^{57}$ Disponível em <https://www.sec.gov/about/laws.shtml $>$, Acesso em 08/11/2016.

${ }^{58}$ Disponível em <https://www.sec.gov/about/laws/soa2002.pdf>, Acesso em 08/11/2016.
} 
informações financeiras e combate firmemente a fraude corporativa e contábil. $^{59}$

\subsubsection{Dodd-Frank Wall Street Reform and Consumer Protection Act} de $2010^{60}$

Promulgada em 21 de julho de 2010 pelo presidente Barack Obama, ela reformulou o ambiente regulatório norte americano em áreas como proteção ao consumidor, restrições às negociações, classificação de créditos, regulação de produtos financeiros, governança corporativa, divulgação de informações, transparências, dentre outros pontos. ${ }^{61}$

\subsubsection{Jumpstart Our Business Startups Act de $2012^{62}$}

Por fim, a lei conhecida como JOBS Act tem como objetivo facilitar e ajudar negócios a angariarem fundos em mercados de capitais por meio de uma redução dos requerimentos regulatórios. ${ }^{63}$

\subsection{Manipulação de mercado pela Internet}

A internet, atualmente, é algo essencial no mercado financeiro. Acesso fácil a dados comparativos de empresas, divulgação de informações, compra e venda de valores mobiliários, tudo isso pode ser feito do seu computador ou até mesmo por um aplicativo no seu celular.

No entanto, apesar dessas facilidades serem, na maior parte, beneficiais ao mercado, elas também abrem as portas para fraudes e manipulações.

\footnotetext{
${ }^{59}$ Disponível em $<$ https://www.sec.gov/about/laws.shtml $>$, Acesso em 08/11/2016.

${ }^{60}$ Disponível em <https://www.sec.gov/about/laws/wallstreetreform-cpa.pdf $>$, Acesso em 08/11/2016.

${ }^{61}$ Disponível em <https://www.sec.gov/about/laws.shtml >, Acesso em 08/11/2016.

62 Disponível em <https://www.gpo.gov/fdsys/pkg/BILLS-112hr3606enr/pdf/BILLS112hr3606enr.pdf $>$, Acesso em 08/11/2016.

${ }^{63}$ Disponível em <https://www.sec.gov/about/laws.shtml $>$, Acesso em 08/11/2016.
} 
Já abordamos, no segundo capítulo, como o nosso sistema falho de transmissão de informações funciona e como ele pode ser abusado. As mesmas teorias se aplicam para a manipulação do mercado de capitais por meio da internet. Você pode utilizar-se das mesmas táticas para disseminar alguma informação com o objetivo de ilicitamente alterar o preço de algum valor mobiliário.

Exemplo de como a mídia pode ser manipulada para influenciar o mercado de capitais é por meio do comunicado à imprensa. Em uma estrutura que privilegia a velocidade do que o conteúdo, o comunicado à imprensa é um prato cheio uma vez que já apresenta todo o conteúdo pronto (notícia nova, já escrita, fonte "confiável"). Nessa linha, o Pew Research Center reafirmou o que Kurt Bardella já havia notado:

"Como a notícia é publicada mais rapidamente, em geral com pouca adição de trabalho jornalístico, a versão oficial de um evento está se tornando mais importante. Nós descobrimos que comunicados oficiais à imprensa geralmente aparecem palavra por palavra nos primeiros relatos de eventos, embora não sejam identificados dessa forma." 6465

Outra questão essencial para o tema são os fóruns de discussão. Utilizados com grande efeito em esquemas de pump and dump, os fóruns se tornam uma grande oportunidade para indivíduos com intenções ilícitas. Muitos dos principais casos de manipulação pela internet no Brasil e nos EUA envolvem, em algum momento, a utilização de fóruns na internet para manipular o preço de valores mobiliários.

De forma a aumentar o controle sobre os usuários de fóruns de discussão, a CVM editou a Instrução n. ${ }^{\circ}$ 380, datada de 23 de dezembro de 2002, a qual estabelece que as corretoras devem guardar os dados dos usuários de seus fóruns, quando sob pseudônimo, por 5 anos. Ainda assim, essa atitude solitária parece precária em face do atual cenário, visto que trata somente da fiscalização (para eventual punição) após o acontecimento

\footnotetext{
64 "And this faster dissemination of news was tied to three other trends. As news is posted faster, often with little enterprise reporting added, the official version of events is becoming more important. We found official press releases often appear word for word in first accounts of events, though often not noted as such."

${ }_{65}$ PEW RESEARCH CENTER. How News Happens. <http://www.journalism.org/2010/01/11/how-news-happens/>, Acesso em 12/11/2016.
} 
do fato.

Sobre o assunto, uma das soluções mais interessantes foi dada pela legislação da Austrália, que conseguiu impor um controle prévio à atuação nos fóruns, por meio do estabelecimento de diretrizes de atuação para os usuários e os moderadores dos fóruns. Por exemplo, caso algum usuário viole tais diretrizes ao comentar no fórum, seu comentário não será deletado, mas sim editado pelo moderador, que deverá explicar exatamente o motivo da edição de tal comentário. ${ }^{66}$

Além disso, também há facilidade do roubo de informações (desde informações "públicas" obtidas em Sites até o roubo de contas, senhas e logins) e a transferência quase imediata de dinheiro pelo mundo são exemplos fáceis de como a tecnologia pode ser utilizada com propósitos ilícitos.

Somando todos esses problemas com o imenso e rápido alcance que a internet possui, é bem fácil notar o desafio peculiar que isso representa para o controle e fiscalização das agências regulatórias.

Como esperado, tanto as legislações quanto as agências regulatórias tem reagido lentamente face à rápida mudança do nosso paradigma.

Nesse quesito, a SEC está se mostrado à frente da CVM. Em 1998 a SEC criou uma área especializada para a fiscalização na internet, chefiada por John Stark. Ademais, também já foram conduzidos estudos sobre a corretagem online na internet, ${ }^{67}$ assim como a SEC já anunciou ${ }^{68}$ ser possível divulgar algumas informações chaves por meio do Facebook e Twitter, desde que seus investidores estejam cientes que tais informações serão divulgadas por esses meios de comunicação.

\footnotetext{
${ }^{66}$ DELORT, Jean-Yves; ARUNASALAM, Bavani; LEUNG, Henry; MILOSAVLJEVIC, Maria. The impact of manipulation in internet stock message boards, In. International Journal of Banking and Finance: Vol. 8: Publicação n. ${ }^{\circ}$ 4, Artigo 1, 1 p. 7. $\langle\underline{h t t p}: / /$ epublications.bond.edu.au/cgi/viewcontent.cgi?article $=1178 \&$ context $=i j b f><$ Acesso em $12 / 11 / 2016$

67 SEC. Special Study: On-Line Brokerage: Keeping Apace of Cyberspace $<$ https://www.sec.gov/news/studies/cyberspace.htm>, Acesso em 08/11/2016.

${ }^{68}$ SEC Says Social Media OK for Company Announcements if Investors Are Alerted $\langle$ https://www.sec.gov/News/PressRelease/Detail/PressRelease/1365171513574〉, Acesso em $08 / 11 / 2016$.
} 


\section{Capítulo 4 - Manipulação de Mercado em Espécie}

\subsection{Pump and Dump}

$\mathrm{O}$ sistema de pump and dump constitui em inflar artificialmente o preço de uma ação para depois vendê-la por um preço muito maior que o seu preço real.

Como explicado pela revista exame, alguma pessoa pega um "mico" da bolsa (ação baixo valor e liquidez) e artificialmente transforma esse mico em um King Kong, utilizando-se de boatos e informações inverídicas ou exageradas para criar expectativas de retornos milionários (fase do Pump). ${ }^{69}$

Uma vez que estas ações possuem baixo valor, qualquer oscilação em seu preço apresenta uma grande alteração percentual - por exemplo, uma ação de $\mathrm{R} \$ 0,30$, que passa valer $\mathrm{R} \$ 0,90$, teve um aumento de apenas 60 centavos, no entanto apresentou um aumento percentual de $200 \%$ - o que pode atrair outros investidores, instigados por aquela movimentação anormal da ação.

Após a compra dessas ações por outros investidores, os autores do golpe vendem suas ações a preços muito mais elevados que o preço real das ações e com margens de lucros altíssimas - utilizando do exemplo acima, a venda pelos golpistas seria feita com um lucro de 100\% (fase do Dump). Com isso, poucas horas depois (ou até mesmo na hora da venda das ações dos golpistas) o preço da ação cai bruscamente e volta a ser mais ou menos o preço original da ação. ${ }^{70}$

Antigamente, esse golpe era muito utilizado por operadores que ligavam diretamente para os investidores, como acontecia no notório filme

\footnotetext{
69 MASSARO, André. Golpes $e$ picaretagens - o "pump and dump". <http://exame.abril.com.br/rede-de-blogs/voce-e-o-dinheiro/2012/03/12/golpes-e-picaretagens-opump-and-dump/>, Acesso em 23/11/2016.

${ }^{70}$ MASSARO, André. Golpes e picaretagens - $o$ "pump and dump". <http://exame.abril.com.br/rede-de-blogs/voce-e-o-dinheiro/2012/03/12/golpes-e-picaretagens-opump-and-dump/>, Acesso em 23/11/2016.
} 
O Lobo de Wall Street. Hoje em dia, o golpe já se tornou mais tecnológico, a maior parte dessas tentativas de golpe são realizadas por meio da internet.

Atualmente, as maneiras mais comuns que os golpistas de pump and dump utilizam são: Sites fazendo boas recomendações para alguma ação, ou envio por email de uma newsletter (supostamente de algum expert em mercado de capitais) ou comentários em fóruns de discussão na internet (normalmente alegando ter uma "fonte confiável"). Além disso, frequentemente, essas ações são de pequenas companhias, pouco negociadas, uma vez que é mais fácil manipular as informações de companhias que tem pouca ou nenhuma informação disponível.

Como explicitado no excelente artigo de Nancy Toross, o pump and dump pela internet é definido como:

"The new "cyber" boiler rooms allow scam artists to conduct sophisticated market manipulations at almost no cost over the Internet from the comfort of their own homes. In four easy steps, a manipulator can consummate the entire fraud. The first step is to set up a site or home page where potential investors can find out about the issuer. In step two, the manipulator, using bulk e-mail or a spamming program, personally contacts potential investors regarding an investment opportunity. In step three, the manipulator begins a "buzz" about the issuer and its shares by posting false information to bulletin boards, newsgroups, and discussion forums. Finally, in step four, the manipulator strengthens the buzz by employing an Internet investment newsletter. It is that easy to hype the stock, and easier still to sell the stock back into the exchanges or over-the-counter markets at a profit and reap the financial rewards of having inflated the stock price." ${ }^{71}$

Por ser algo que acontece de maneira muito rápida e fora do âmbito controlado do mercado de capitais, não é possível aplicar o controle prévio das empresas reguladoras, o controle passa a ser a posteriori, mediante a análise das oscilações, seus motivos e pessoas envolvidas.

Dessa forma, a $\mathrm{SEC}^{72}$ e muitos outros Sites $^{73}$ indicam que os investidores tomem as seguintes precauções para evitar golpes de pump and

\footnotetext{
${ }^{71}$ Nancy Toross, Double-Click on This: Keeping Pace with On-Line Market Manipulation, 32 LOY. L.A. L. REV. 1399 (1999) p.1420-1421.

${ }^{72}$ SEC. Pump\&Dump.con:Tips for Avoiding Stock Scams on the Internet. <https://www.sec.gov/investor/pubs/pump.htm> Acesso em 23/11/2016.

${ }^{73}$ Tips For Avoiding "Pump and Dump” Scams. < http://www.stopbrokerfraud.com/tips-foravoiding-pump-and-dump-scams.html >, Acesso em 23/11/2016, e BORGES, Diego. Pump and dump: saiba o que é e como evitar esse tipo de "golpe" com ações. <http://www.infomoney.com.br/onde-investir/noticia/2391116/pump-and-dump-saiba-que-comoevitar-esse-tipo-golpe>, Acesso em 23/11/2016.
} 
dump na internet: (i) checar sempre a fonte da informação - qualquer informação deve ser confirmada por uma pesquisa independente para que a informação seja considerada legítima; (ii) descobrir onde a ação é negociada - ações de pequenas companhias muitas vezes não cumprem os requisitos para serem listadas em bolsas reconhecidas como NASDAQ ou na BOVESPA. Ações que são negociadas em mercado de balcão (over-thecounter market) possuem mais risco e são mais suscetíveis à golpes; e (iii) fazer uma pesquisa independente - é necessário sempre fazer uma pesquisa independente, confirmando as alegações feitas sobre novos produtos ou oportunidades da companhia e analisando as suas informações financeiras.

\subsection{Marking the Open/Marking the Close (Marking)}

O Marking é uma tática antiga, utilizada muito antes da internet. No entanto, a simplicidade, rapidez e flexibilidade que internet permite na compra e venda das ações, bem como seu amplo alcance, facilita em muito, a utilização do Marking.

Assim como o pump and dump, o Marking também tem por objetivo manipular o preço da ação. No entanto, a grande diferença está no modo utilizado para alterar os preços.

Enquanto o pump and dump utiliza os meios de comunicação para enviar recomendações ou dicas, de forma a rapidamente aumentar o preço de uma ação, o Marking manipula o preço intradia da ação para atribuir um preço não real à ação em questão.

Esta manipulação pode ser utilizada com objetivos diversos. Um deles seria para inflar artificialmente o preço das ações para que o envolvido possa vender suas ações por um preço superior ao real. ${ }^{74}$ Outra possibilidade seria evitar chamadas de margem (ou diminuir o valor a ser

\footnotetext{
${ }^{74}$ Conforme foi utilizado no caso da Metynis, que será analisado abaixo.
} 
pago) ou o reforço de garantias ${ }^{75}$. Muitas vezes o valor das ações dadas em garantia em operações de margem ou em outras operações é verificado no início ou no fim do dia, permitindo que o Marking camufle o preço da ação e evite essas chamadas ou reforços. ${ }^{76}$

\footnotetext{
${ }^{75} \mathrm{Um}$ excelente exemplo de reforço de garantia poderia ser feito no caso da Enron, a qual, em diversas oportunidades, garantia suas operações com as próprias ações. Nesse caso, caso as ações se mantenham no mesmo preço ou aumentem, a garantia se mantém. Caso as ações diminuam de preço, o valor dado em garantia será menor que o valor das obrigações garantidas e, consequentemente, será necessário um reforço da garantia.

${ }^{76}$ Casos como esses são comuns nos Estados Unidos. Vejam: Administrative Proceeding File No. 3-9040. In the matter of Alexander Sheshunoff <https://www.sec.gov/litigation/admin/3437419.txt>, Acesso em 11/11/2016; SEC SETTLES "MARKING THE CLOSE" MANIPULATION CASE AGAINST JOHN P. VENNERS <https://www.sec.gov/litigation/litreleases/lr16613.htm〉, Acesso em 11/11/2016; e Admin. Proc. File No. 3-8510. In the matter of Adrian C. Havill $\langle$ https://www.sec.gov/litigation/opinions/3440726.txt $>$, Acesso em 11/11/2016.
} 


\section{Capítulo 5 - Análise de Casos nos EUA}

\subsection{SEC vs. Kenneth Terrel, Jason Wyckoff, Adam Altman e Joanne Colt ${ }^{77}$}

\subsubsection{O Sistema de Manipulação}

Neste caso, Douglas Colt criou o website fast-trade.com, e, com a posterior ajuda de Kenneth Terrel, Jason Wyckoff, Adan Altman (seus colegas de faculdade) e Joanne Colt (sua mãe), utilizou um sistema de pump and dump para manipular o preço de quatro ações diferentes. Por meio desse esquema, os envolvidos lucraram mais de US\$345.000,00.

Basicamente, o sistema funcionava da seguinte forma: os envolvidos compravam ações de empresas pequenas, pouco conhecidas e pouco negociadas. Logo após a compra das ações, os envolvidos enviavam aos membros do fast-trade.com uma recomendação para comprar os papéis da companhia em questão.

Apenas o grande volume de ações negociado pelos envolvidos (que por três vezes foi maior que $150 \%$ do volume médio diário de negociação daquelas ações) e a recomendação que o seu website enviava para os potenciais investidores foram suficientes para aumentar o preço das ações em até $700 \%$, o que fazia com que os envolvidos tivessem lucros de até $500 \%$ em até uma hora após a recomendação pelo fast-trade.com.

No entanto, para que o esquema funcionasse corretamente, era necessário que o website aumentasse cada vez mais sua base de subscritores. Para tanto, o website era anunciado por meio de posts em fóruns de discussão na internet, método pelo qual a sua base de subscritores aumentou para mais de 9.000 pessoas em apenas dois meses.

Ali, os envolvidos criaram diversas identidades on-line falsas e

\footnotetext{
77 Administrative Proceeding File No. 3-10154. In the Matter of Kenneth Terrell. <https://www.sec.gov/litigation/admin/34-42483.htm>, Acesso em 11/11/2016.
} 
fizeram postagens em fóruns de discussão financeiros como o yahoo.com e ragingbull.com. Eles utilizavam as diversas identidades falsas para aumentar a credibilidade do website e ludibriar os potenciais investidores, fornecendo informações enganosas de como os lucros foram obtidos no fast-trades.com ou das suas conexões com o website.

Ademais, além de anunciar e apoiar o website, Kenneth Terrell também defendia o fast-trades.com de acusações de manipulação de mercado por parte outros usuários. Sempre escondendo sua verdadeira identidade, ele argumentou que a atividade do website estaria dentro da lei. Mais pra frente, ele também mentiu ao afirmar (por meio de um perfil falso) que teria se comunicado com a SEC sobre a empresa, mas que nada poderia ser feito uma vez que o negócio seria legal.

Além disso, o site oferecia, por tempo limitado, um período de teste grátis de 6 meses. No entanto, essa oferta "por tempo limitado" nunca encerrou e os subscritores jamais pagaram um centavo de inscrição ao website.

Contudo, de maneira a se resguardarem, os envolvidos colocaram um disclaimer no fast-trade.com que dizia que dizia que eles poderiam vender ou comprar as ações indicadas feitas por eles mesmos a qualquer momento. Após o primeiro caso de manipulação eles revisaram a redação para informar que os representantes da fast-trades.com podiam, e em muitas vezes o faziam, investir ou deter ações nas companhias que o fasttrades.com indicava. Além disso "elucidavam" ao informar que os representantes da fast-trades.com se reservavam o direito de comprar ou vender as ações sindicadas pela fast-trade.com a qualquer momento.

Um fato curioso é que antes de investir fortemente no seu esquema, Douglas Colt decidiu testar o tamanho do impacto que a sua recomendação teria no mercado por meio da recomendação da ação da Electrosource, Inc. Pouco após a sua recomendação, o valor da ação subiu em $35 \%$. 


\subsubsection{O Primeiro caso - Apache Medical Systems, Inc.}

Em 16 de fevereiro de 1999, os envolvidos escolheram seu primeiro alvo, Apache Medical Systems, Inc., uma companhia com média diária de 11.700 ações negociadas. Eles compraram 5.000 ações (mais de $40 \%$ da média diária) pelo preço de US\$1,0625 cada, e colocaram uma ordem de venda sobre elas no valor de US\$4,00. Em vinte minutos, entre o momento que a compra foi feita e que o fast-trades.com fez a sua recomendação, o preço por ação já havia subido para US $\$ 1,50$ (aumento de $41 \%$ ).

Depois que a recomendação do fast-trades.com saiu para seus subscritores, a quantidade de ações negociadas e o preço delas subiu significativamente. Naquele dia foram negociadas 1.085 .600 ações que chegaram a valer até US $\$ 7,9375$ por ação (um aumento de mais de $600 \%$ das compras iniciais pelos envolvidos).

Após ver a grande movimentação, os envolvidos subiram a ordem de venda para US\$6,00 e tiveram seus lotes de ações foram vendidos entre US\$6,00 e US\$7,75. Meia hora após a recomendação os envolvidos já haviam se livrado de todas as suas ações e angariaram um lucro de US\$27.937,50. Horas depois, o preço das ações já havia caído bruscamente. Dias depois, o preço das ações já estava em uma fração do seu preço inicial.

\subsubsection{O Segundo Caso - Option Care}

Em 24 de fevereiro de 1999, a Option Care foi escolhida como segundo alvo, uma companhia com média diária de 14.000 ações negociadas. Eles (exceto Joanne Colt) compraram 10.000 ações (aproximadamente $70 \%$ da média diária) pelo preço de US $\$ 1,625$ cada e colocaram uma ordem de venda sobre elas no valor de US\$5,00.

Após a recomendação do fast-trades.com chegar para seus subscritores, a quantidade de ações negociadas e o preço delas novamente subiu significativamente. Naquele dia foram negociadas 1.290 .100 ações que chegaram a valer até US\$5,875 por ação (um aumento de mais de 
$250 \%$ das compras iniciais pelos envolvidos).

No mesmo modus operandi, pouco depois das serem recomendadas, as ações dos envolvidos foram vendidas pelo preço de US\$5.375, totalizando um lucro de US $\$ 37.500$. Horas depois, novamente, o preço das ações já havia caído bruscamente. Dias depois, o preço das ações já estava em uma fração do seu preço inicial.

Uma questão curiosa nessa manipulação foi que Joanne Colt, comprou outras 14.000 ações da Option Care, mas cometeu um grave erro. Ela esperou para comprar as ações após a recomendação do fast-trades.com, o que fez que com ela comprasse as ações por US5,00/US\$5,50 ao invés de US $\$ 1,625$.

Com isso, para tentar conseguir lucro, ela tentou vender suas ações entre pelo peço de US $\$ 7,00$ a US $\$ 9,00$, e acabou falhando miseravelmente em sua tentativa. Nesse meio tempo, os preços das ações começaram a cair para menos de US5,00. Joanne entrou em pânico e vendeu todas as suas ações por preços entre US\$3,56 e US $\$ 2,88$, acumulando um prejuízo de mais de US $\$ 24.000,00$ em meros 25 minutos.

No entanto, isso não assustou Joanne, mas sim confirmou suas convicções sobre o funcionamento do esquema. Para pagar suas dívidas e acumular dinheiro para a próxima investida, ela retirou US\$15.000,00 da sua conta de aposentadoria e mais US\$11.000,00 do seu seguro de vida.

\subsubsection{A Terceira Investida - American Education Corp.}

A terceira investida foi contra a American Education Corp., em 5 de março de 1999, a qual possuía média diária de 3.500 ações negociadas. Eles (exceto Joanne Colt) compraram 19.000 ações e colocaram uma ordem de venda sobre elas no valor de US\$6,50. Já Joanne Colt comprou 10.750 ações e colocou uma ordem de venda sobre elas no valor entre US $\$ 4,50$ e US $\$ 7,00$.

Aqui, no entanto, novas pessoas foram envolvidas na jogada. Um 
amigo de Douglas Colt comprou, a seu mando, 2.000 ações e colocou uma ordem de venda sobre elas no valor de US\$5,00. Adicionalmente, Joanne Colt também avisou a um amigo - que não se envolvia com mercado de capitais a aproximadamente 8 anos, diga-se de passagem - o qual comprou 4.533 ações, além de estabelecer ordens de venda sobre elas em valores variando de US $\$ 4,00$ a US $\$ 5,00$.

Em três horas e meia, da primeira compra até a recomendação do website, os envolvidos já haviam negociado 36.283 ações da American Education Corp - mais de $1.000 \%$ da média diária de ações negociadas. Somente essas negociações já fizeram o preço das ações subir de iniciais US\$1,25 para US\$1,625, configurando um aumento de $30 \%$.

Ademais, os envolvidos foram mais audaciosos nessa investida. Ao invés de comprar todas as ações de uma só vez, como fizeram nas duas últimas oportunidades, eles compraram as ações em blocos para que o preço já fosse inflacionar o preço mesmo antes da recomendação do fasttrades.com.

Após os subscritores receberam a recomendação do fast-trades.com, a quantidade de ações negociadas e o preço delas, outra vez, subiu significativamente. Naquele dia foram negociadas 842.600 ações que chegaram a valer até US\$10,00 por ação (um aumento de mais de $700 \%$ das compras iniciais pelos envolvidos).

Neste caso, Douglas Colt e seus comparsas obtiveram um lucro de US\$41.093,75, o amigo de Douglas obteve um lucro US\$3.500,00, Joanne Colt lucrou US\$59.984,37 e o amigo de Joanne lucrou US\$15.899,00.

Não é nenhuma surpresa que, novamente, horas depois, novamente, o preço das ações já havia caído bruscamente. Muito menos que, dias depois, o preço das ações já estava em uma fração do seu preço inicial.

\subsubsection{A Última Investida - Artecon, Inc.}

A última investida foi contra a Artecon, Inc., em 10 de março de 
1999, a qual possuía média diária de 33.000 ações negociadas. Eles (exceto Joanne Colt) compraram 17,282 ações e o amigo de Douglas Colt comprou 1.000 ações. Já Joanne Colt comprou 17.500 ações e seu amigo comprou 11.730 .

Em duas horas, da primeira compra até a recomendação do website, os envolvidos já haviam negociado 51.512 ações da American Education Corp - mais de $100 \%$ da média diária de ações negociadas. Somente essas negociações já fizeram o preço das ações subir de iniciais US\$1,125 para US $\$ 1,375$, configurando um aumento de $22 \%$.

Após os subscritores receberam a recomendação do fast-trades.com, mais uma vez, a quantidade de ações negociadas e o preço delas, subiu significativamente. Naquele dia foram negociadas 4.581 .000 ações que chegaram a valer até US\$6,00 por ação (um aumento de mais de 400\% das compras iniciais pelos envolvidos).

Nessa investida, Douglas Colt e seus comparsas obtiveram um lucro de US\$66.516,36, o amigo de Douglas lucrou US\$15.474,37, Joanne Colt lucrou US\$47.081,25 e o amigo de Joanne lucrou US\$34.937,00.

Como esperado, horas depois, o preço das ações já havia caído bruscamente. Da mesma forma, dias depois, o preço das ações já estava em uma fração do seu preço inicial.

\subsubsection{Consequências}

Após os acontecimentos acima narrados, a SEC começou uma investigação sobre o caso e, em 2 de março de 2000, foi celebrado um acordo entre a SEC e os envolvidos. Tanto o amigo de Douglas Colt quanto o amigo de Joanne Colt não foram acusados ou implicados no esquema.

No entanto, é necessário destacar que esse acordo causou uma grande polêmica. Foram três os pontos mais contestados: (i) nenhum dos envolvidos admitiu ou negou ter realizado qualquer ilícito no caso, mas apenas se comprometeram a não praticar mais nenhum ilícito do tipo no 
futuro; (ii) nenhum dos envolvidos foi multado; (iii) apesar de terem concordado em devolver o dinheiro obtido pelo esquema, a SEC dispensou esse pagamento tendo em vista que os envolvidos não tinham capacidade de pagar.

A faculdade de Georgetown, a qual Douglas Colt, Kenneth Terrell, Jason Wycoff e Adam Altman cursavam, informou que não tinha planos de punir os alunos pois eles já estariam passando por uma humilhação pública e que já sofreriam futuras consequências em bancas de admissão da ordem de advocacia. ${ }^{78}$

$\mathrm{O}$ acordo foi muito criticado por juristas norte americanos, um professor norte americano ressaltou, inclusive, que se as pessoas não são obrigadas a devolver os seus ganhos ilícitos, isso seria um convite para as pessoas cometerem fraudes e tentarem não ser pegas. ${ }^{79}$

Já a SEC defendeu outro ponto de vista. Eles consideram o acordo justo e que as consequências foram severas para todos. Ademais, também destacaram que após a análise da situação financeira dos envolvidos eles não teriam condição de pagar os montantes envolvidos. ${ }^{80}$

\subsection{SEC vs Lambros Ballas ${ }^{81}$}

Lambros Ballas, um corretor registrado perante a SEC, aproveitou-se de como o nosso falho sistema de transmissão de informações funciona para emitir diversos falsos comunicados à imprensa, de forma a manipular o preço de diversas ações.

\footnotetext{
${ }^{78}$ BERENSON, Alex. S.E.C. Reaches Settlement in Web-Based 'Pump and Dump' Case. <http://www.nytimes.com/2000/03/03/business/sec-reaches-settlement-in-web-based-pump-anddump-case.html >, Acesso em 08/11/2016.

${ }^{79}$ BERENSON, Alex. S.E.C. Reaches Settlement in Web-Based 'Pump and Dump' Case. <http://www.nytimes.com/2000/03/03/business/sec-reaches-settlement-in-web-based-pump-anddump-case.html >, Acesso em 08/11/2016.

${ }^{80}$ BERENSON, Alex. S.E.C. Reaches Settlement in Web-Based 'Pump and Dump' Case. <http://www.nytimes.com/2000/03/03/business/sec-reaches-settlement-in-web-based-pump-anddump-case.html >, Acesso em 08/11/2016.

${ }^{81}$ Disponível em $<$ https://www.sec.gov/litigation/complaints/2009/comp21259.pdf>, Acesso em 23/11/2016.
} 
Assim como outros, Lambro Ballas conseguiu compreender como funciona a transmissão de informações na nova era e, durante quatro dias, emitiu falsos comunicados à imprensa em nome de grandes companhias abertas como o Google, Microsoft e Wall Disney. Para completar, ele ainda fingiu ser um investidor de tais companhias em um fórum do Yahoo, disponibilizando os links dos comunicados falsos que ele mesmo fabricara.

\subsubsection{Discovery Laboratories, Inc.}

O primeiro alvo de Ballas foi a Discovery Laboratory, Inc., uma companhia aberta registrada na NASDAQ que desenvolve remédios e terapias para doenças respiratórias, em especial, à época, uma droga denominada Surfaxin. Em 29 de setembro de 2009 as suas ações estavam cotadas a US\$1,00 por ação.

Também em 29 de setembro de 2009, Ballas se registrou em um Site que divulga comunicados à imprensa (www.pr-inside.com), utilizando-se de uma mistura de informações pessoais no seu cadastro. Ainda na mesma data, Ballas enviou um comunicado à imprensa ao pr-inside.com, em nome da Discovery Laboratory, informando falsamente que a droga Surfaxin teria sido aprovada pela FDA sem nenhuma restrição. Apesar de tudo sobre o comunicado ser falso, o mesmo foi publicado às 19:15.

Às 19:31, Ballas criou uma conta no Yahoo, sob o pseudônimo de "stevegaffinancial", o nome de um antigo colega de trabalho. Sob este pseudônimo, Ballas divulgou no fórum que "A APROVAÇÃO DA FDA ACABOU DE CHEGAR", ${ }^{82}$ incluindo, inclusive, um link para o comunicado à imprensa "oficial".

Não satisfeito, às 20:36, Ballas enviou novo comunicado à imprensa, desta vez em nome da própria FDA, anunciando que a FDA havia aprovado a droga da Discovery Laboratory.

A questão é que Ballas havia indicado a seus clientes a compra das

82 "FDA APPROVAL JUST CAME IN". 
ações da Discovery Laboratory, realizada por volta de US\$1,11 por ação. Após a sua manipulação, na abertura do mercado em 30 de setembro de 2009, as ações da Discovery Laboratory tinham subido 46\%. E estavam valendo US1,63.

Após toda essa movimentação, a verdadeira Discovery Labs emitiu um comunicado à imprensa informando que havia boas expectativas para aprovação do Sufaxin, mas não afirmou já ter obtido a aprovação da FDA. No final do dia a ação já tinha caído para US\$1,36.

\subsubsection{IMAX / Disney}

A IMAX Corporation, notória empresa de som e imagem cinematográfica, foi o segundo alvo de Ballas. Em 30 de setembro de 2009, apenas um dia após sua última empreitada, Ballas emitiu um novo falso comunicado à imprensa por meio do pr-inside.com, desta vez em nome de um suposto repórter da Associated Press (empresa de telecomunicação), alegando que a Disney teria comprado a IMAX por US\$1,5 bilhão e incluindo um suposto comentário do CEO da IMAX.

Novamente o comunicado era completamente falso e, mais uma vez, o comunicado foi publicado pelo pr-inside.com, agora antes das negociações do mercado começarem, às 5:43.

Às 6 horas da manhã, Ballas voltou ao fórum de discussões no Site do Yahoo, sob o pseudônimo de "desmatia", e iniciou um tópico com o título "Ai meu deus, não acredito que a IMAX FOI COMPRADA" ${ }^{83}$, alegando que:

"DISNEY IS BUYING THEM OUT THE PRESS RELEASES .ARE ALL OVER THE INTERNET. HERE IS 2 THE LINK, MY BROKER JUST CALLED ME TO TELL ME AT THE CRACK OF DAWN I 3 OWN IT AROUND \$1020 PER SHARE, AND LOOKING TO OPEN AROUND \$20 PER 4 SHARE."

Às 6:30, usando o mesmo pseudônimo, Ballas iniciou novo tópico no fórum do Yahoo, falando sobre a suposta compra, alegando que o valor de

\footnotetext{
83 "oh my god, i can't believe it !MAX BOUGHT OUT"
} 
compra das ações seria $90 \%$ do atual valor das ações e discutindo como a mudança de administração iria beneficiar a IMAX. Com o mesmo modo de agir, Ballas também disponibilizou o link para um segundo comunicado falso que ele mesmo havia enviado ao pr-inseides.com.

Às 6:40, Ballas atacou novamente. Desta vez o título do tópico no fórum do Yahoo era "Disney comprou a IMAX por US\$18 por ação UHUUUUL", ${ }^{84}$ fornecendo, inclusive, mais um falso comunicado à imprensa elaborado por ele e enviado ao pr-insides.com.

Com essas falsas informações, o valor das ações da IMAX aumentaram. Às 9:56, a IMAX divulgou um comunicado à imprensa, esse verdadeiro, negando a sua compra pela Disney e informando que não havia nenhuma negociação para uma potencial aquisição pela Disney.

\subsubsection{Local.com}

A última manipulação de Ballas envolveu a Local.com (empresa de serviços de pesquisa na internet), e os gigantes Microsoft e Google. Em 1 de outubro de 2009, logo após os dois casos acima narrados, Ballas comprou 5.000 ações da Local.com a US\$5,33 cada.

Em seguida, às 16:15, Ballas enviou ao Site www.12pressrelease.com um comunicado à imprensa, em nome de uma companhia de relações públicas, alegando que a Microsoft havia adquirido a Local.com, citando, inclusive, o CEO da Local.com que supostamente teria alegado estar muito feliz com a transação e que o local.com trabalharia com afinco para melhor o sistema de pesquisa da Microsoft, o bing.com. O Comunicado foi divulgado imediatamente pelo 12pressrelease.com.

Utilizando-se das exatas mesmas táticas, usando seu primeiro pseudônimo, divulgou no fórum do Yahoo a venda da local.com, disponibilizando, também, o link do seu falso comunicado à imprensa.

Mas dessa vez, ele foi mais engenhoso. Além de divulgar o

\footnotetext{
84 "disney bought out imax for $\$ 18$ per share WHO HOODOO."
} 
comunicado pelo 12pressrelease.com, Ballas enviou novo falso comunicado ao www.wiredprnews.com. Com isso, às 17:43, Ballas, sob o seu segundo pseudônimo, iniciou uma nova discussão sobre a suposta venda da local.com, alegando que o Site 12pressrelease.com não seria tão confiável, mas que agora o wiredprnes.com também havia divulgado a mesma informação.

Em seguida, Ballas continuou sua atuação nos fóruns de discussão do Yahoo, utilizando os dois pseudônimos, iniciando novas discussões sobre a falsa aquisição com tópicos como "It's official folks, right 25 direct of[sic] the newswire, LOCAL BOUGHT OUT WOO HOOOO. READ IT FOR 26 YOURSELF.".

Com isso, as ações da local.com aumentaram em quase $80 \%$, chegando a atingir US\$9,65 no dia, o que levou Ballas a obter um lucro de US $\$ 21.600,00$ na venda de suas 5.000 ações.

A local.com demorou a reagir a essa informação e, somente as 21:30, informou ao mercado que o comunicado era falso e que não havia nenhuma negociação em curso com a Microsoft.

No entanto, Ballas não parou por ai. No dia seguinte, 2 de outubro de 2009, ele enviou novo falso comunicado à wireprnews.com alegando que agora o Google estaria adquirindo local.com. A wiredprnews.com (finalmente) suspeitou que o comunicado poderia ser uma fraude e se recusou a publicá-lo sem maiores informações.

Todavia, Ballas compreendia amplamente como o nosso sistema funcionava e simplesmente levou seu comunicado falso para outro Site, o www.einpressiwire.com, que o publicou por US\$49,95. Assim, após a publicação, utilizou, novamente, seus pseudônimos no fórum do Yahoo para divulgar a falsa informação.

\subsubsection{Resultado}

Devido a sua atuação fraudulenta no mercado, a SEC entrou com 


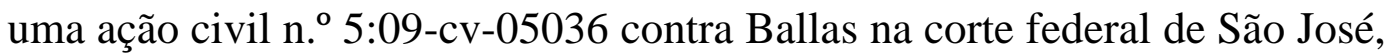
Califórnia., o qual admitiu ser culpado e ter manipulado o mercado por meio de comunicados à imprensa, com o objetivo de inflar artificialmente o preço das ações. $^{85}$

\footnotetext{
${ }^{85}$ U.S. ATTORNEY'S OFFICE. Securities Broker Pleads Guilty to Issuing False Press Releases to Inflate Stock Prices. <https://archives.fbi.gov/archives/sanfrancisco/pressreleases/2010/sf031110.htm $>$, Acesso em 23/11/2016.
} 


\section{Capítulo 6 - Análise de casos no Brasil}

\subsection{Inquérito Administrativo CVM n.- TA-RJ2001/6226 - Ciro Orenstein Ribeiro Tourinho ${ }^{86}$}

O primeiro caso julgado pela CVM de manipulação de mercado pela internet foi um caso peculiar. $\mathrm{O}$ acusado Ciro Orenstein Ribeiro Tourinho tentou e falhou na sua tentativa de manipular o mercado.

O caso começou no fórum de discussão da InvestShop Corretora de Valores Mobiliários e Câmbio S/A. Nele, onde qualquer pessoa registrada poderia tecer comentários, discutir assuntos e opinar nos diversos posts do website, tudo sobre a proteção de um pseudônimo. No entanto, a verdadeira identidade da pessoa por trás do pseudônimo só era conferida caso ela se tornasse cliente da corretora.

Então, no dia 23 de março de 2001, os pseudônimos "baldacci" e "Birilo" trocaram mensagens no fórum da Investshop ambos alegando que os negócios com as ações da a Companhia Siderúrgica Paulista S/A Cosipa seriam suspensos para o anúncio de sua recompra a um preço superior ao de mercado, informações estas que seriam baseadas em uma fonte interna na CVM.

Acontece que os dois pseudônimos pertenciam a Ciro Tourinho (o registro de "baldacci" utilizava apenas dados fictícios, enquanto "Birilo" utilizava seus dados reais), que simulara conversas no fórum de discussões para dar maior credibilidade à informação, bem como inventara sobre a suposta fonte interna da CVM.

À época das mensagens, Ciro Tourinho detinha 110.000 ações da Cosipa, adquiridas até um mês antes. Sua intenção, então, ficou clara: o envolvido iria se utilizar do esquema de pump and dump para inflacionar

\footnotetext{
${ }^{86}$ Inquérito Administrativo CVM n. ${ }^{\circ}$ TA-RJ2001/6226. Disponível em: $<$ http://www.cvm.gov.br/export/sites/cvm/sancionadores/sancionador/anexos/2003/20030515 PA S RJ20016226.pdf>, Acesso em 23/11/2016.
} 
artificialmente as ações da Cosip e em seguida livrar-se delas por um preço maior que o valor real.

A grande peculiaridade do caso foi que Ciro falhou miseravelmente na sua tentativa de manipular o mercado. Nos pregões seguintes, não houve nenhuma mudança significativa no valor das ações da Cosip.

No entanto, apesar de sua atitude não ter causado nenhum prejuízo ao mercado, a CVM entendeu que houve a intenção de manipular o mercado, nos termos da Instrução CVM n. ${ }^{\circ}$ 8/79, e o condenou à pena de proibição de atuar no mercado de valores mobiliários pelo prazo de um ano.

A conta para Ciro, todavia, foi bem mais alta. De acordo com a própria decisão da CVM, ele precisou pedir demissão do emprego para não ser demitido, ficou desempregado por 6 meses, teve que vender seu carro para quitar dívida de mais de $\mathrm{R} \$ 19.000,00$ com a Nestlé, que o financiara e foi forçado a vender todas as ações da Cosipa com um prejuízo de aproximadamente $30 \%$ para pagar todas as suas dívidas.

\subsection{Processo Administrativo Sancionador CVM n. RJ2013/5194 - Metynis (Marambaia) ${ }^{87}$}

\subsubsection{Quem é quem}

No presente processo administrativo os acusados foram a Metynis Participações S.A. e Marcelo Impellizieri de Moraes Bastos. Além deles, peça essencial para compreensão do caso é a Marambaia Energia Renovável S.A., sociedade na qual a Metynis detia 45\% do capital social.

A Metynis era controlada pela RCJP Equity S.A. e, em 5 de junho de 2009 adquiriu 45\% da ações de emissão da Marambaia.

Marcelo Bastos tinha um grande envolvimento com todas as companhias. Ele era diretor da RCJP, sócio da Metynis e membro do

\footnotetext{
${ }^{87}$ Processo Administrativo Sancionador CVM n ${ }^{\circ}$ RJ2013/5194. $<$ http://www.cvm.gov.br/export/sites/cvm/sancionadores/sancionador/anexos/2014/20141219 PA S RJ20135194.pdf>, Acesso em 08/11/2016.
} 
conselho de administração da Marambaia.

Já a Marambaia era uma empresa não operacional, com a publicação das demonstrações financeiras em atraso e sem receitas. Segundo as demonstrações financeiras de 2009, os ativos da Marambaia eram de R \$ 29 milhões, sendo R \$ 16 milhões de créditos a receber de partes relacionadas e R \$ 11 milhões de créditos tributários decorrentes do crédito prêmio do IPI créditos com chances remotíssimas de serem recebidos.

A aquisição da participação na Marambaia pela Metynis, anunciada em 5 de junho de 2009, seguida pela matéria do Valor Econômico, a qual detalhava o plano de investimento e soerguimento da Marambaia, causou um aumento das expectativas e da liquidez das ações da Marambaia. Em fóruns na internet, os usuários estavam com expectativas altas.

Outro fator essencial para a grande expectativa foi o fato relevante, divulgado ao mercado em 1 de março de 2010, o qual anunciava a celebração de um memorando de entendimentos com o Grupo J. Pessoa, com o objetivo de firmar uma parceira e alavancar a Marambaia.

\subsubsection{Marking the Open/Close}

Durante 2009 e 2010, uma das táticas utilizadas pelos acusados para manipular o preço das ações da Marambaia foi o Marking, de maneira a possibilitar que a Metynis se desfizesse de sua participação na Marambaia. Para tentar disfarçar essas vendas, os acusados utilizaram mais de uma corretora.

Inicialmente, durante 2009 e o início de 2010, Marcelo ou a própria Metynis compravam lotes de ações no primeiro leilão do dia a preços maiores que a cotação do dia anterior (Marking the Open) e no leilão de fechamento, também para elevar os preços (Marking the Close). Nessas operações, Marcelo efetuou 96 compras de pequenos lotes de ação, sendo 92 a preços mais elevados que o negócio anterior. Da mesma forma agiu a Metynis, que executou 386 compras de pequenos lotes de ação sendo a 
maior parte (326) de pequenos lotes de ação, dessas operações 248 foram fechadas a preços mais elevados que o negócio anterior e outras 117 foram fechadas em preços iguais ao negócio anterior.

As táticas surtiram o efeito desejado e os preços das ações da Marambaia aumentaram. Para manter a movimentação e o preço das ações razoavelmente alto, os acusados vendiam suas ações a preços mais baixos durante o dia, mesmo que incorressem em um pequeno prejuízo monetário. Em geral, os acusados vendiam e compravam a mesma quantidade de ações nos períodos em que negociavam.

No entanto, o comportamento deles começou a mudar em 12 de abril de 2010. Nesta data, a Marambaia alienou 5\% da sua participação e atrasou propositalmente a divulgação do aviso ao mercado requerido pela instrução 358 da CVM. Esse atraso permitiu que a Metynis e Marcelo vendessem uma grande quantidade das suas ações a um preço superior ao que teria sido obtido com a divulgação de tal fato relevante. Para comprovar o ponto, um mês depois, o mercado foi avisado da alienação e isso causou e uma queda imediata do valor das ações da Maramabaia de $14,5 \%$.

Após o negócio com o Grupo J. Pessoa não ir para frente (em agosto de 2010), os acusados passaram a constantemente vender mais ações do que compravam e também começaram a apresentar lucro líquido ao final das transações. Dessa forma, os acusados obtinham lucro com as suas vendas e puxavam o preço das ações da Marambaia para cima, além de atrair a atenção de possíveis investidores.

\subsubsection{A atuação nos fóruns de internet.}

Além disso, Marcelo atuou ativamente nos fóruns de internet para influenciar o preço das ações. Registrado sob o nome de Marcel Moraes e utilizando o pseudônimo de "marceloimb", o acusado não fez um bom trabalho em disfarçar sua participação. Marcel Moraes é nada mais que um pedaço do seu nome (Marcelo Impellizieri de Moraes Bastos) e 
marceloimb é seu nome mais as iniciais de seu sobrenome (Marcelo Impellizieri de Moraes Bastos). O fato era tão óbvio que a própria defesa perante a CVM confirmou que marceloimb era, de fato, o acusado.

Ao entrar no fórum, em 29 de julho de 2009, Marcelo se apresentou da seguinte forma:

\begin{abstract}
"Sou Diretor de uma companhia que eh acionista da Marambaia, alem de membro do Conselho de Administraçao da companhia. Nao falo pela companhia por que nao tenho poderes de representaçao pelo Estatuto, mas gostaria de comentar aqui no forum informalmente,se possivel esclarecendo duvidas de outros investidores que, como eu, acreditam no trabalho da companhia, respeitados os limites da Instruçao CVM 358. Meus comentarios sao pessoais meus e nem a companhia da qual sou administrador, nem a companhia objeto dos comentarios tem qualquer ligaçao com as opinioes aqui eventualmente manifestadas por mim. Abraços a todos. (...)"
\end{abstract}

Com isso, ao anunciar os importantes fatos de que ele era acionista relevante e membro do conselho da Marambaia, conseguiu atrair a atenção dos demais investidores.

Após sua primeira participação, Marcelo passou a participar ativamente do fórum. Divulgava boas perspectivas para o futuro da Marambaia, pedia para os investidores continuarem acreditando na reestruturação da Marambaia, afirmava que a Companhia estava trabalhando forte para sua melhora. Em um dos casos Marcelo afirmou que:

\footnotetext{
"Eu tenho limitaçoes, mas a companhia esta fazendo todo o possivel para garantir que o mercado veja a açao como um bom investimento, que tera retorno no longo prazo para quem acreditar que a reestruturaçao vai produzir valor para os acionistas"
}

Marcelo enfrentou alguns focos de resistência no fórum. Apenas uma hora após seu post inicial, um participante do fórum perguntou como uma corretora tinha vendido uma quantidade tão grande de ações uma vez que a Marambaia só possuía 5\% das ações no free float. Depois outro usuário questionou que as vendas de lotes da ações da Marambaia deveriam vir de algum de seus controladores. Em ambas as ocasiões, Marcelo refutou as implicações feitas (apesar de verdadeiras), na primeira afirmando que a conselho da Marambaia estava empenhado em atualizar "informações, transparência e liquidez dos papeis da Companhia [Marambaia]" e na 
segunda afirmando que não faria sentido o controlador estar negociando as ações e dizendo ao usuário que:

"Muli, acho que vc nao esta interpretando corretamente. A reestruturaçao da empresa eh para valer. Nao tem isso nao. Estamos pavimentando o caminho para que a nossa açao de retorno seguro e bom para os acionistas que acreditarem no projeto da companhia. Nao eh uma açao de picaretas. Pode acreditar."

No final de 2009, após discussões com outros usuários sobre a grande quantidade de vendas das ações da Marambaia, na penúltima participação de Marcelo no fórum, mais uma vez ele reafirmou as boas perspectivas da Companhia e o trabalho forte da administração da Marambaia. Em 25 de março de 2010, Marcelo fez sua última participação e retirou-se do fórum.

\subsubsection{Os Fatos (ir)Relevantes}

Ademais, a Marambaia divulgou uma grande quantidade de fatos relevantes e comunicados ao mercado para manter o interesse dos investidores e aumentar a liquidez das ações da Marambaia.

Entre 6 de agosto de 2009 e 13 de maio de 2010 a Marambaia divulgou 9 fatos relevantes/comunicados ao mercado, dos quais quase nenhum foi concretizado. O mercado foi informado por diversas vezes sobre perspectivas futuras de negócios e o andamento de negociações.

Por exemplo, a parceria com o Grupo J. Pessoa foi anunciada primeiramente em 29 de outubro de 2009, em que a Marambaia estaria negociando com um grupo sucroalcooleiro. Em 18 de dezembro de 2009 foi comunicado que tal negociação ainda estava em andamento. Em 1 de março de 2010, a possível parceria foi anunciada, e, em 26 de março de 2010, ela ainda estava em andamento.

Porém, os fatos realmente relevantes eram propositalmente deixados de lado. Como já exposto, a alienação de participação relevante da Metynis na Marambaia foi atrasada em um mês. Adicionalmente, a não conclusão do negócio com o Grupo J. Pessoa foi reportado pelo Valor Econômico, em 6 
de agosto de 2010, no qual o presidente do Grupo J. Pessoa disse ter desfeito o negócio há cerca de um mês.

\subsubsection{O Resultado}

Tendo em vista os fatos acima narrados, foi iniciado o processo administrativo sancionador CVM n. ${ }^{\circ}$ RJ2013/5194, para apurar as responsabilidades dos acusados pela infração do Item II, "b" da Instrução CVM 08/79.

Após análise do caso pelo colegiado, a Metynis e Marcelo foram condenados, por unanimidade, pela prática de manipulação de preços. A Metynis foi condenada à multa pecuniária no valor de $\mathrm{R} \$ 500$ mil, já Marcelo foi proibido de atuar direta ou indiretamente, como investidor, em qualquer mercado organizado de valores mobiliários pelo prazo de cinco anos. 


\section{Capítulo 7 - Conclusão}

Depois de toda a pesquisa e estudo sobre o assunto deste trabalho, a frase atribuída a Sócrates "Só sei que nada sei" parece se encaixar como uma luva. A infinidade de casos, possibilidades e questões, todas altamente complexas, é inerente ao tema de manipulação de mercado. A questão aqui analisada se mostrou tão grande e complexa que somente a análise dos casos aqui mencionados já se mostrou muito maior que o esperado e, por isso, não foram abordados casos interessantíssimos com o de Jonathan Lebed e Eike Batista, dentre muitos outros.

A primeira conclusão que podemos chegar é que nosso sistema de transmissão de informações é extremamente suscetível a influências externas. Não há questionamento sobre conflitos de interesses ao se publicar qualquer artigo, nem ao menos um juízo de bom senso dos editores ao receber uma informação de uma parte claramente interessada em divulgar a informação.

A segunda conclusão é que o grande dilema do Direito - que as leis não acompanham a evolução da sociedade - é de extrema relevância para esse tema. Tanto a legislação brasileira quanto a norte americana se mostram defasadas em face da nossa realidade e a CVM e a SEC estão constantemente tentando acompanhar e se atualizar em face dos rápidos avanços tecnológicos da nossa realidade.

A terceira conclusão é que a atuação fiscalizatória da SEC e da CVM, após o acontecimento da manipulação, tem se provado muito efetiva. Inúmeros casos de manipulação foram metodicamente investigados e julgados, mesmo que um tempos após a ocorrência do fato. Isso demonstra que, apesar de o controle a priori, via legislação, estar deficitário, as autarquias tem se adaptado e evoluído para conseguir exercer um eficaz e efetivo controle a posteriori das manipulações de mercado..

A quarta conclusão é que todos os tipos de companhias estão sujeitas 
à manipulação pela internet. Como acima exposto, não somente as penny stocks são alvo de manipulação, até mesmo grandes companhias (como até mesmo o Google e a Microsoft, mesmo que indiretamente), listadas em notórias bolsas de valores como BOVESPA ou NASDAQ e com informações prontamente disponíveis na internet, são alvos e/ou são utilizadas nas tramoias de manipulação.

No entanto, a maior expectativa desse trabalho é aumentar a reflexão sobre um assunto tão importante e pouco abordado, especialmente no Brasil. Mesmo nos EUA, aonde o assunto já debatido há anos, a legislação e atuação da SEC mostram-se atrasadas em relação à atual realidade. Consequentemente, o Brasil e a CVM, que ainda estão engatinhando em comparação com os EUA e a SEC, quase não tem pesquisas, estudos, doutrina e até mesmo decisões sobre o assunto. 


\section{BIBLIOGRAFIA}

- First stock ticker debuts. <http://www.history.com/this-day-in-history/firststock-ticker-debuts $>$, Acesso em 12/11/2016.

- It took radio 38 years to reach 50 million people... <http://digitalstats.blogspot.com.br/2011/04/it-took-radio-38-years-to-reach-50.html >, Acesso em 23/11/2016.

- Internet Users. 〈http://www.internetlivestats.com/internet-users/\#trend > Acesso em 23/11/2016.

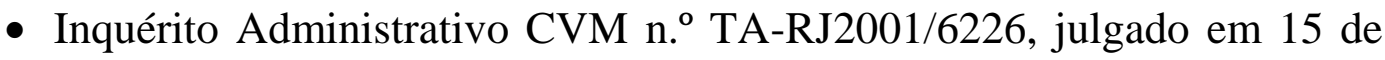
maio de 2003, Relatora: Norma Jonssen Parente. Disponível em <http://www.cvm.gov.br/export/sites/cvm/sancionadores/sancionador/anexos/2003/2 0030515 PAS RJ20016226.pdf>, Acesso em 23/11/2016.

- COUTINHO, Filipe. Agência contratada pelo PT paga R\$20 mil de salário a criador de Dilma Bolada. <http://epoca.globo.com/tempo/noticia/2015/08/agencia-contratada-pelo-pt-paga-r20-mil-de-salario-dilma-bolada.html>, Acesso em 23/11/2016.

- Como Ganhar Dinheiro Na Internet Com Programa De Afiliados. <http://www.maisrendaagora.com/como-ganhar-dinheiro-na-internet-programa-deafiliados/>, Acesso em 23/11/2016.

- MCFARLANE, Greg. How Does Google Make its Money? <http://www.investopedia.com/stock-analysis/2012/what-does-google-actually-makemoney-from-goog1121.aspx>, Acesso em 08/11/2016.

- How Does Google Make Money? <http://www.bbc.co.uk/guides/z9x6bk7>, Acesso em 08/11/2016

- HOLIDAY, Ryan. Acredite, Estou mentindo: confissões deum manipulador de mídia. $1^{a}$ ed. - São Paulo. Companhia Editora Nacional, 2012.

- FLINT, Joe. Time Warner wants more revenue from TMZ. <http://articles.latimes.com/2009/dec/09/business/la-fi-ct-tmz9-2009dec09>, Acesso em $12 / 11 / 2016$

- MCINTYRE, Douglas A. TMZ.com Valuation Tops $\$ 100$ Million .<http://www.marketwatch.com/story/tmzcom-valuation-tops-100-million-2010-0103> Acesso em 12/11/2016.

- EQUIPE TMZ. Brutal Rihanna Photos Surface < http://www.tmz.com/2011/02/24/rihanna-photos-brutal-beating-chris-brown-attack-policeattack/>, Acesso em 12/11/2016.

- EQUIPE TMZ. Michael Jackson Dies

<http://www.tmz.com/2009/06/25/michael-jackson-dies-death-dead-cardiac-arrest/>, Acesso em 12/11/2016.

- $\quad$ EQUIPE TMZ. The JFK Photo That Could Have Changed History. <http://www.tmz.com/2009/12/28/president-john-f-kennedy-photograph-jfk-photo-boat-yatchnude-naked-women-mediterranean-sea-jackie-kennedy-ted-kennedy-senator-george-smatherselection/>, Acesso em 12/11/2016.

- TMZ Falls For JFK Photo Hoax

<http://www.thesmokinggun.com/documents/celebrity/tmz-falls-jfk-photo-hoax $>$, 
Acesso em 12/11/2016.

- What do the big tech blogs such as TechCrunch or Mashable look for when they hire writers? <https://www.quora.com/What-do-the-big-tech-blogs-suchas-TechCrunch-or-Mashable-look-for-when-they-hire-writers>, Acesso em 12/11/2016.

- ROWSE, Darren. Weblogs Inc Pays \$4 per Post to Bloggers. $<$ http://www.problogger.net/weblogs-inc-pays-4-per-post-to-bloggers/>, Acesso em 12/11/2016.

- $\quad$ KAPLAN, David. Updated: Seeking Alpha On Track To Pay Its Bloggers \$1.2 Million This Year. <https://gigaom.com/2011/07/05/419-seeking-alphaon-track-to-pay-its-bloggers-1-2-million-this-year/>, Acesso em 12/11/2016

- BLODGET, Henry. More Than You Ever Wanted To Know About The Economics Of The Online News Business -- A TWEETIFESTO. $<$ http://www.businessinsider.com/henry-blodget-more-than-you-ever-wanted-toknow-about-the-economics-of-the-online-news-business-a-tweetifesto-20103?op=1/\#>, Acesso em 12/11/2016.

- $\quad$ THIER, Dave. Tucker Max's Rejected Twitter Campaign and Stab at Celebrity Endorsement. <http://www.forbes.com/sites/davidthier/2012/02/07/tuckermaxs-rejected-twitter-campaign-and-stab-at-celebrity-endorsement/\#75d2b8af6c72>, Acesso em 12/11/2016.

- VARNEY, Chelsea. Celebrity Twitter Ads: Regulations, Allegations and Selling Out. <https://www.brandwatch.com/blog/celebrity-twitter-endorsementsregulations-allegations-and-selling-out/>, Acesso em 12/11/2016.

- VEJA SÂO PAULO. Conar Adverte Gabriela Pugliesi por publicidade ilegal. <http://vejasp.abril.com.br/materia/conar-adverte-gabriela-pugliesipor-publicidade-ilegal >, Acesso em 12/11/2016.

- ROBERTSON, Lindsay. The Dos and Don'ts of Online Publicity,

For Some Reason. <http://lindsayrobertson-blog.tumblr.com/post/330892541/the-dosand-donts-of-online-publicity-for-some >, Acesso em 12/11/2016.

- NEWSWEEK. The Dos and Don'ts of Online Publicity, For Some Reason. $\quad<$ http://newsweek.tumblr.com/post/330924245/the-dos-and-donts-of-onlinepublicity-for-some>, Acesso em 12/11/2016.

- National Survey Finds Majority of Journalists Now Depend on Social Media for Story Research. <http://www.cision.com/us/about/news/2010-pressreleases/national-survey-finds-majority-of-journalists-now-depend-on-social-media-for-storyresearch/>, Acesso em 12/11/2016.

- LIZZA, Ryan. DON'T LOOK BACK. < http://www.newyorker.com/magazine/2011/01/24/dont-look-back-ryan-lizza>, Acesso em 12/11/2016.

- $\quad$ NPR STAFF. The Music Man Behind 'Entourage' Shares His Secret. <http://www.npr.org/2011/11/20/142558220/the-music-man-behind-entourage-shares-hissecret>, Acesso em 12/11/2016.

- Desafio Aceito 25 - Fazer a Coreia do Norte Campeã da Copa! <http://www.naosalvo.com.br/desafio-aceito-25-fazer-da-coreia-do-norte-campea-da-copa/>, Acesso em 12/11/2016. 
- Pawlenty budgets with an eye on 2012. <http://www.politico.com/story/2010/05/pawlenty-budgets-with-an-eye-on-2012-037358>, Acesso em 12/11/2016.

- $\quad$ PETERS, Jeremy W. Political Blogs Are Ready to Flood Campaign Trail 〈http://www.nytimes.com/2011/01/30/business/media/30blogs.html〉, Acesso em 12/11/2016.

- $\quad$ MUSKAL, Michael. Mitt Romney, Tim Pawlenty show support for Wisconsin governor < http://articles.latimes.com/2011/feb/24/news/la-pn-wisconsin-goppolitics-20110224>, Acesso em 12/11/2016.

- $\quad$ SANDRINI, João. Decisão do STJ confirma absolvição do investidor Naji Nahas. 〈http://www1.folha.uol.com.br/folha/dinheiro/ult91u97763.shtml>, Acesso em 23/11/2016.

- $\quad 7^{\mathrm{a}}$ Vara da Justiça Federal de Porto Alegre. Ação Penal n. ${ }^{o}$ 506709618.2012.4.04.7100/RS, Juiz Federal Guilherme Beltrami, Porto Alegre, 7 de novembro de 2016. Disponível em <http://www.cvm.gov.br/export/sites/cvm/noticias/anexos/2016/20161111-sentencamundial.pdf $>$, Acesso em 23/11/2016.

- MACEY, Jonathan; MILLER, Geoffrey. Origin of the Blue Sky Laws.

$\langle$ http://digitalcommons.law.yale.edu/cgi/viewcontent.cgi?article=2679\&context=fss papers $>$, Acesso em 08/11/2016.

- LOSS \& SELIGMAN, Fundamentals of securities regulation $-5^{\text {a }}$ Edição. Aspen Publishers, 2004.

- ALVAREZ \& ASTARITA. Introduction to the Blue Sky Laws $<$ http://www.seclaw.com/bluesky.htm> Acesso em 08/11/2016.

- INVESTOPEDIA. Blue Sky Laws and the Securities Act of 1933. <http://www.investopedia.com/exam-guide/series-7/securities-markets/blue-sky-laws.asp>, Acesso em 08/11/2016

- Blue sky law. <https://www.law.cornell.edu/wex/blue sky law>, Acesso em $08 / 11 / 2016$

- $\quad\langle$ https://www.sec.gov/about/laws/sa33.pdf>, Acesso em 07/11/2016.

- $\quad\langle$ https://www.sec.gov/about/laws/sea34.pdf>, Acesso em 07/11/2016.

- SARKAR, Deepa. Securities Exchange Act of 1934. https://www.law.cornell.edu/wex/securities exchange act of 1934, Acesso em 08/11/2016.

- $\quad$ http://www.ecfr.gov/cgi-bin/text-idx?node=17:4.0.1.1.1\&rgn=div5\#sg17.4.240.a.sg0>, Acesso em 08/11/2016.

- $\quad\langle$ https://www.sec.gov/about/laws/tia39.pdf>, Acesso em 08/11/2016.

- $\quad\langle$ https://www.sec.gov/about/laws.shtml >, Acesso em 08/11/2016.

- $\quad\langle$ https://www.sec.gov/about/laws/ica40.pdf>, Acesso em 08/11/2016.

- $\quad\langle$ https://www.sec.gov/about/laws/iaa40.pdf $>$, Acesso em 08/11/2016.

- $\quad\langle$ https://www.sec.gov/about/laws/soa2002.pdf>, Acesso em 08/11/2016.

- $\quad\langle$ https://www.sec.gov/about/laws/wallstreetreform-cpa.pdf>, Acesso

em 08/11/2016. 
- $\quad$ https://www.gpo.gov/fdsys/pkg/BILLS-112hr3606enr/pdf/BILLS-112hr3606enr.pdf>, Acesso em 08/11/2016.

- PEW RESEARCH CENTER. How News Happens. <http://www.journalism.org/2010/01/11/how-news-happens/>, Acesso em 12/11/2016.

- $\quad$ DELORT, Jean-Yves; ARUNASALAM, Bavani; LEUNG, Henry; MILOSAVLJEVIC, Maria. The impact of manipulation in internet stock message boards, In. International Journal of Banking and Finance: Vol. 8: Publicação n. ${ }^{\circ}$ 4, Artigo 1, p. 7.

$<$ http://epublications.bond.edu.au/cgi/viewcontent.cgi?article=1178\&context=ijbf $><$ Acesso em 12/11/2016.

- $\quad$ SEC. Special Study: On-Line Brokerage: Keeping Apace of Cyberspace <https://www.sec.gov/news/studies/cyberspace.htm>, Acesso em 08/11/2016.

- SEC Says Social Media OK for Company Announcements if Investors Are Alerted <https://www.sec.gov/News/PressRelease/Detail/PressRelease/1365171513574>, Acesso em 08/11/2016.

- MASSARO, André. Golpes e picaretagens - o "pump and dump". <http://exame.abril.com.br/rede-de-blogs/voce-e-o-dinheiro/2012/03/12/golpes-epicaretagens-o-pump-and-dump/>, Acesso em 23/11/2016.

- $\quad$ Nancy Toross, Double-Click on This: Keeping Pace with On-Line Market Manipulation, 32 LOY. L.A. L. REV. 1399 (1999)

- SEC. Pump\&Dump.con:Tips for Avoiding Stock Scams on the Internet. <https://www.sec.gov/investor/pubs/pump.htm> Acesso em 23/11/2016. " Tips For Avoiding "Pump and Dump" Scams. <http://www.stopbrokerfraud.com/tips-for-avoiding-pump-and-dump-scams.html>, Acesso em 23/11/2016

- $\quad$ BORGES, Diego. Pump and dump: saiba o que é e como evitar esse tipo de "golpe" com ações. <http://www.infomoney.com.br/ondeinvestir/noticia/2391116/pump-and-dump-saiba-que-como-evitar-esse-tipo-golpe>, Acesso em 23/11/2016.

- Administrative Proceeding File No. 3-9040. In the matter of Alexander Sheshunoff <https://www.sec.gov/litigation/admin/3437419.txt>, Acesso em 11/11/2016;

- SEC SETTLES "MARKING THE CLOSE" MANIPULATION CASE AGAINST JOHN P. VENNERS <https://www.sec.gov/litigation/litreleases//r16613.htm>, Acesso em 11/11/2016;

- Admin. Proc. File No. 3-8510. In the matter of Adrian C. Havill <https://www.sec.gov/litigation/opinions/3440726.txt>, Acesso em 11/11/2016.

- $\quad$ https://www.sec.gov/litigation/complaints/2009/comp21259.pdf>, Acesso em 23/11/2016.

- $\quad$ BERENSON, Alex. S.E.C. Reaches Settlement in Web-Based 'Pump and Dump' Case. <http://www.nytimes.com/2000/03/03/business/sec-reachessettlement-in-web-based-pump-and-dump-case.html >, Acesso em 08/11/2016. 
- U.S. ATTORNEY'S OFFICE. Securities Broker Pleads Guilty to Issuing False Press Releases to Inflate Stock Prices. 〈https://archives.fbi.gov/archives/sanfrancisco/press-releases/2010/sf031110.htm〉, Acesso em 23/11/2016.

- Inquérito Administrativo CVM n. ${ }^{\circ}$ TA-RJ2001/6226. Disponível em: <http://www.cvm.gov.br/export/sites/cvm/sancionadores/sancionador/anexos/2003/20030515 PAS RJ20016226.pdf>, Acesso em 23/11/2016.

- Processo Administrativo Sancionador CVM no RJ2013/5194. <http://www.cvm.gov.br/export/sites/cvm/sancionadores/sancionador/anexos/2014/20141219 PAS RJ20135194.pdf >, Acesso em 08/11/2016. 